\title{
Self-potential monitoring of a thermal pulse advecting through a preferential flow path
}

\author{
S. J. Ikard ${ }^{1}$ and A. Revil ${ }^{1,2}$
}

Key Words: Dams, Seepage, Monitoring, Self-potential; Thermoelectric effect 
22 Abstract. There is a need to develop new non-intrusive geophysical methods to detect

23 preferential flow paths in heterogeneous porous media. A laboratory experiment is performed to

24 non-invasively localize a preferential flow pathway in a sandbox using a heat pulse monitored by

25 time-lapse self-potential measurements. Our goal is to investigate the amplitude of the intrinsic

26 thermoelectric self-potential anomalies and the ability of this method to track preferential flow

27 paths. A negative self-potential anomaly (-10 to $-15 \mathrm{mV}$ with respect to the background signals)

28 is observed at the surface of the tank after hot water is injected in the upstream reservoir during

29 steady state flow between the upstream and downstream reservoirs of the sandbox. Repeating the

30 same experiment with the same volume of water injected upstream, but at the same temperature

31 as the background pore water, produces a negligible self-potential anomaly. The negative self-

32 potential anomaly is possibly associated with an intrinsic thermoelectric effect, with the

33 temperature dependence of the streaming potential coupling coefficient, or with an apparent

34 thermoelectric effect associated with the temperature dependence of the electrodes themselves.

35 We model the experiment in 3D using a finite element code. Our results show that time-lapse

36 self-potential signals can be used to track the position of traveling heat flow pulses in saturated

37 porous materials, and therefore to find preferential flow pathways, especially in a very permeable

38 environment and in real time. The numerical model and the data allows quantifying the intrinsic

39 thermoelectric coupling coefficient, which is on the order of -0.3 to $-1.8 \mathrm{mV}$ per degree Celsius.

40 The temperature dependence of the streaming potential during the experiment is negligible with

41 respect to the intrinsic thermoelectric coupling. However, the temperature dependence of the

42 potential of the electrodes needs to be accounted for and is far from being negligible if the

43 electrodes experience temperature changes. 


\section{Introduction}

The self-potential method is a passive geophysical method that is remotely sensitive to any thermodynamic force affecting the motion of electrical charge carriers in a porous medium (e.g., Revil and Linde, 2006; Revil, 2007). These thermodynamic forces include the pressure head (streaming potential, e.g. Abaza and Clyde, 1969), the gradient of the concentration (diffusion potential, Maineult et al., 2005, 2006, Martínez-Pagán et al., 2010; Straface and De Biase, 2013), and the temperature gradient (thermoelectric effect, Leinov et al., 2010; Revil et al., 2013). Any of these thermodynamic forces can be the source of a source current density (Revil, 2007), which generates in turn, in the electrically conductive ground, an electrical field that can be remotely monitored.

A number of papers have been published in using self-potential signals (measured without any specific triggering effects) to identify preferential flow paths in dams and embankments (Gex, 1980, Corwin, 1985; AlSaigh et al., 1994, Sheffer and Howie, 2001; Song et al., 2005; Rozycki et al., 2006; Bolève et al., 2007, 2009, 2012). However, this purely passive mapping approach is not always characterized by a good signal-to-noise ratio. We have recently developed a better approach, called the SMART test, to illuminate preferential flow channels in dams and embankments. The SMART test consists in injecting a pulse of salty water upstream and in monitoring the advection of the salt plume using time-lapse self-potential measurements (Ikard et al., 2012). This "active" method is more precise than the conventional approach and can also be used to invert the permeability field when combined with time-lapse resistivity measurements and in situ sampling of the pore salinity in downstream wells (Jardani et al., 
field, generates an electrical current density perturbation that can be followed intrusively (Maineult et al., 2005, 2006) or non-intrusively ((Martínez-Pagán et al., 2010; Bolève et al., 2011) with the self-potential method. However, it is often forbidden, for legal reasons and water quality concerns, to inject salty water into an upstream reservoir.

The idea we follow in this paper is to extend the SMART approach by replacing the salt tracer test by a heat pulse test (T-SMART), the temperature can be eventually be lower than the background temperature). We consider the T-SMART approach more eco-friendly. In this case, the resulting self-potential signals are possibly thermoelectric in nature. In presence of a temperature field, we may also need to consider the effect of temperature on the streaming potential associated with the flow of the ground water (e.g., Somasundaran and Kulkani, 1973; Ishido and Mizutani, 1981; Revil et al., 1999a, b). Little is known, however, about the fundamental physical principles governing the thermoelectric effect in porous media in presence of flow. Recent laboratory works on the thermoelectric effect include the work of Leinov et al. (2010) and a theoretical model can be found for instance in Revil (1999). Recently, Revil et al. (2013) have successfully used the thermoelectric effect to localize the burning front of a coal seam fire at a depth of $15 \mathrm{~m}$ in Colorado. While there are other geophysical methods that can identify heat pulses, like electrical resistivity tomography (e.g., Hermans et al., 2012), only the self-potential method can be used in real time to follow the heat pulse in a strongly advectiondominated system.

In this paper, we develop the concept of the T-SMART test and we apply this new test to the localization of a preferential flow channel using the injection of a heat tracer test and monitoring non-intrusively the migration of this heat pulse using the self-potential method. In section 2, we present the theoretical background for modeling intrinsic thermoelectric potentials 
91 and their origin during heat advection and conduction through porous media. In section 3 , we

92 describe a laboratory experiment performed to localize a preferential flow channel in a sandbox.

93 In Section 4, we perform a numerical experiment aimed at understand the laboratory results and 94 to provide a value to the intrinsic thermoelectric coupling coefficient.

\section{2. Theoretical Background}

\section{2.1. Ground Water Flow}

We first present the flow equation in a partially saturated or fully saturated porous material. We solve below the generalized Richards equation with the van Genuchten parametrization for the relative permeability and the capillary pressure in an isotropic unconfined aquifer. Hysteresis will be neglected. The governing equation for the flow of the water phase is given by (Richards, 1931),

$$
\left[C_{e}+s_{e} S\right] \frac{\partial \psi}{\partial t}+\nabla \cdot \mathbf{u}=0
$$
pressure heads, respectively, $C_{e}=\partial \theta / \partial \psi$ denotes the specific moisture capacity (in $\mathrm{m}^{-1}$ ), $\theta$ is the water content (dimensionless), $s_{e}$ is the effective saturation, $S$ is the (poro-elastic) storage coefficient at saturation $\left(\mathrm{m}^{-1}\right)$, and $t$ is time (in $\mathrm{s}$ ). The effective saturation is related to the relative saturation of the water phase by $s_{e}=\left(s_{w}-s_{w}^{r}\right) /\left(1-s_{w}^{r}\right)$ where $\theta=s_{w} \phi$ and $\phi$ 109 (dimensionless) represents the total connected porosity of the material. The hydraulic 110 conductivity $K\left(\right.$ in $\mathrm{m} \mathrm{s}^{-1}$ ) is related to the relative permeability $k_{r}$ (dimensionless) and to the 111 hydraulic conductivity at saturation $K_{s}\left(\mathrm{~m} \mathrm{~s}^{-1}\right)$ by $K=k_{r} K_{s}$. Using the van Genuchten-Mualem 
112 model (van Genuchten 1980; Mualem 1986), the effective saturation, the relative permeability,

113 the specific moisture capacity, and the water content are defined by,

$$
s_{e}=\left\{\begin{array}{l}
\frac{1}{\left[1+|\alpha \psi|^{n}\right]^{m}}, \psi<0 \\
1, \psi \geq 0
\end{array}\right.
$$

$$
k_{r}=\left\{\begin{array}{l}
S_{e}^{l}\left[1-\left(1-S_{e}^{\frac{1}{m}}\right)^{m}\right]^{2}, \psi<0 \\
1, \psi \geq 0
\end{array}\right.
$$

$$
C_{e}=\left\{\begin{array}{l}
\frac{\alpha m}{1-m}\left(\varphi-\theta_{r}\right) s_{e}^{\frac{1}{m}}\left(1-s_{e}^{\frac{1}{m}}\right)^{m}, \psi<0 \\
0, \psi \geq 0
\end{array}\right.
$$

$$
\theta=\left\{\begin{array}{l}
\theta_{r}+s_{e}\left(\phi-\theta_{r}\right), \psi<0 \\
\phi, \psi \geq 0
\end{array}\right.
$$

respectively, where $\theta_{r}$ is the residual water content $\left(\theta_{r}=s_{w}^{r} \phi\right)$, and $\alpha, n, m \approx 1-1 / n$, and $L$ are parameters that characterize the porous material (van Genuchten, 1980; Mualem, 1986). All these parameters will be independently determined for the experiment reported in Section 3.

121 Thermo-osmosis and electro-osmosis correspond to the influence of the thermal gradient and 122 electrical field on the Darcy velocity, respectively. We consider these effects as negligible (see 123 Sill, 1983 for a discussion of these effects).

\subsection{Heat Flow}

We assume below that local thermal equilibrium between the fluid and solid phases is

127 reached at any time. Indeed the characteristic time to reach thermal equilibrium for a silica grain 128 of diameter $d$ immersed in a background of uniform temperature is $\tau=d^{2} /(4 \alpha)$ where 
129 130 131

132 the coarse channel, see below). As this characteristic time is much smaller than the characteristic 133 134 135 136 137 continuity equation for heat,

$\alpha=\lambda_{S} /\left(\rho_{S} \mathrm{C}_{p}\right)$ denotes the thermal diffusivity of silica $\left(\alpha=1.4 \times 10^{-6} \mathrm{~m}^{2} \mathrm{~s}^{-1}\right), \lambda_{s}$ corresponds to the thermal conductivity of silica, $\rho_{S}$ its mass density, and $\mathrm{C}_{p}$ its heat capacity at constant pressure. This yields in turn a characteristic time of $0.3 \mathrm{~s}$ for $d=1.4 \times 10^{-3} \mathrm{~m}$ (grain diameter for time associated with the transport of the heat pulse in the tank ( $>10$ minutes), the assumption of local thermal equilibrium is checked.

We consider the flow of heat in partially saturated porous material described by Eq. (6) obtained by combining Fourier's law (the constitutive equation for the heat flux) with the

$$
\nabla \cdot\left(-\lambda \nabla T+\rho_{w} C_{w} T \mathbf{u}\right)+\rho C \frac{\partial T}{\partial t}=Q
$$

where $T$ is the average temperature of the porous medium (in $\mathrm{K}$ ), $\lambda$ (in $\mathrm{W} \mathrm{m}^{-1} \mathrm{~K}^{-1}$ ) is the thermal conductivity of the porous material, $\rho_{w}$ and $\rho\left(\mathrm{kg} \mathrm{m}^{-3}\right)$ denote the mass density of the pore water and the bulk mass density of the porous material (with the pore fluids), respectively, $C_{w}$ and $C$ (in $\mathrm{J} \mathrm{kg}^{-1} \mathrm{~K}^{-1}$ ) are the heat capacity of the pore water per unit mass and the bulk heat capacity of the porous material (with the pore fluids) per unit mass, respectively, and $Q$ denotes the heat source (in $\mathrm{W} \mathrm{m}^{-3}$, positive for a source and negative for a sink). For unsaturated porous media, we determine the bulk heat capacity per unit volume and the bulk thermal conductivity by (e.g., Luo et al., 1994),

$$
\rho C=(1-\phi) \rho_{s} C_{s}+\phi s_{w} \rho_{w} C_{w}+\phi\left(1-s_{w}\right) \rho_{a} C_{a}
$$

and

$$
\lambda=\lambda_{s}^{1-\phi} \lambda_{w}^{\phi s_{w}} \lambda_{s}^{\phi\left(1-s_{w}\right)}
$$


150 151

respectively, and where $C_{\xi}, \rho_{\xi}$, and $\lambda_{\xi}$ denotes the volumetric heat capacity, density, and thermal conductivity of phase $\xi$ (solid s, pore water, w, and air, a).

Because the pore fluid viscosity and density entering the hydraulic problem are temperature-dependent, the hydraulic and the thermal problems are coupled. However, we will neglect the back-effects of temperature on the flow properties because we are considering a small heat pulse. This assumption is discussed in Appendix A. In this appendix, we show that the temperature dependence of the hydraulic conductivity is roughly $2 \%$ per degree Celsius, therefore the heat pulse is characterized by a slightly higher hydraulic conductivity. However this change is confined to the region characterized by a change in temperature. Outside this region, the hydraulic conductivity remains the same and therefore the kinetics of the flow of the heat pulse should not be affected too much by small temperature changes.

\subsection{The self-potential problem}

We describe now the self-potential problem in porous media in presence of the flow of the pore water and a temperature gradient. The first step is to define the source current density associated with the flow of the pore water (streaming current) and the source current density associated with the temperature gradient. The first term is associated with the drag of the effective excess of charge $\hat{Q}_{V}$ (at saturation and expressed in $\mathrm{C} \mathrm{m}^{-3}$ ) caused by the flow of the pore water described by the Darcy velocity $\mathbf{u}$. The second term is controlled by the temperature gradient. The sum of these two terms corresponds to the total source current density $\mathbf{j}_{S}$ (in $\mathrm{A} \mathrm{m}^{-}$

$70 \quad 2$ )

$$
\mathbf{j}_{S}=\frac{\hat{Q}_{V}}{s_{w}} \mathbf{u}+C_{T} \sigma\left(s_{w}\right) \nabla T,
$$


172 where $\sigma$ (in $\mathrm{S} \mathrm{m}^{-1}$ ) denotes the (saturation-dependent) electrical conductivity of the porous 173 material, and $C_{T}$ (in $\mathrm{V} \mathrm{K}^{-1}$ ) is the thermoelectric coupling coefficient defined below. For $\mathrm{pH}$ 174 comprised between 5 and 8, Jardani et al. (2007) found that the effective charge density $\hat{Q}_{V}$ is 175 related to the permeability at saturation $k$ (in $\mathrm{m}^{2}$ ) and they developed the following empirical 176 relationship,

$$
\log _{10} \hat{Q}_{V}=-9.2-0.82 \log _{10} k
$$

178 Equation (10) holds for a broad range of porous rocks and soils (Revil and Mahardika, 2013).

179 In conductive materials, the source current density $\mathbf{j}_{S}$ is responsible for an electrical field 180 and the tangential component of this electrical field is measured at the ground surface (e.g., Revil 181 et al., 2012). With respect to the macroscopic electrical field, the generalized Ohm's law for the 182 total current density $\mathbf{j}\left(\mathrm{A} \mathrm{m}^{-2}\right)$ is written as,

$$
\mathbf{j}=\sigma \mathbf{E}+\mathbf{j}_{S},
$$

184 where $\mathbf{E}=-\nabla \varphi$ (in $\mathrm{V} \mathrm{m}^{-1}$ ) denotes the electrical field and $\varphi$ (in $\mathrm{V}$ ) the self-potential field. The 185 first term of Eq. (11) corresponds to the classical Ohm's law of electrical conduction while the 186 second term corresponds to the source current density associated it the advective drag of the 187 electrical charges contained in the pore water and the thermoelectric source current density. 188 From Eqs. (9) and (11), the streaming potential and intrinsic thermoelectric coupling coefficients 189 of the porous material are defined by,

$$
\begin{aligned}
& C_{S}=\left(\frac{\partial \varphi}{\partial h}\right)_{\mathbf{j}=0, \nabla \mathrm{T}=0}, \\
& C_{T}=\left(\frac{\partial \varphi}{\partial T}\right)_{\mathbf{j}=0, \mathbf{u}=0},
\end{aligned}
$$


192 and are expressed in $\mathrm{V} \mathrm{m}^{-1}$ and $\mathrm{V} \mathrm{K}^{-1}$ (or $\mathrm{V}^{\circ} \mathrm{C}^{-1}$ ), respectively. In Eq. (13), the thermoelectric 193 coupling coefficient is only properly defined in absence of flow and when the total current 194 density is zero. In a recent work, Revil et al. (2013) obtained a value of the thermoelectric 195 coupling coefficient of $-0.5 \mathrm{mV}^{\circ} \mathrm{C}^{-1}$. The negative polarity implies that positive temperature 196 anomalies (increase in temperature) should be associated with negative self-potential anomalies.

197 Eqs. (9) and (11) are combined with a conservation equation for the electrical charge that 198 is written as $\nabla \cdot \mathbf{j}=0$ in the quasi-static limit of the Maxwell equations (Sill, 1983). The 199 combination of these equations yields the following elliptic partial differential equation for the 200 self-potential $\varphi($ Sill, 1983),

$$
\nabla \cdot(\sigma \nabla \varphi)=\nabla \cdot \mathbf{j}_{S}
$$

202 The right-hand side of Eq. (14) corresponds to the self-potential source term. The divergence of 203 the source current density $\mathbf{j}_{S}$ given by Eq. (9),

$$
\nabla \cdot \mathbf{j}_{S}=\nabla\left(\frac{\hat{Q}_{V}}{s_{w}}\right) \cdot \mathbf{u}+\frac{\hat{Q}_{V}}{s_{w}} \nabla \cdot \mathbf{u}+\nabla\left(C_{T} \sigma\right) \cdot \nabla T+C_{T} \sigma \nabla^{2} T
$$

205 We see from Eq. (15) that there is a variety of source term associated with the flow pattern (the 206 two first terms of the right-hand side of Eq. 15) and thermal effects (two last terms of the right207 hand side of Eq. 15). properties of the porous soils and rocks; the connected porosity $\phi$ and the cation exchange 210 capacity CEC, by (Revil, 2013)

$$
\sigma=\frac{1}{F} s_{w}^{n} \sigma_{w}+s_{w}{ }^{p} \sigma_{S}
$$

212 where the surface conductivity is defined as, 


$$
\sigma_{S} \approx\left(\frac{1}{F \phi}\right) \rho_{S} \beta_{(+)}(1-f) \mathrm{CEC}
$$

214 In Eq. (16), $\sigma_{w}$ (in $\mathrm{S} \mathrm{m}^{-1}$ ) corresponds to the pore water conductivity, $\sigma_{S}\left(\right.$ in $\mathrm{S} \mathrm{m}^{-1}$ ) denotes the 215 electrical conductivity associated with the electro-migration of the cations in the diffuse layer 216 coating the surface of the grains (see Figure 1a and 1b), $F$ (dimensionless) is the formation factor 217 related to the porosity by Archie's law $F=\phi^{-m}$ (Archie, 1942), where $m$ is called the 218 cementation exponent or first Archie exponent and is typically in the range $1.5-2.5, n$ is the 219 second Archie's exponent (also called the saturation exponent), $p=n-1$ (see Revil, 2013), $\rho_{S}$ 220 (in $\mathrm{kg} \mathrm{m}^{-3}$ ) denotes the mass density of the solid phase (typically $2650 \mathrm{~kg} \mathrm{~m}^{-3}$ for silicates), $\beta_{(+)}$ $221\left(\mathrm{~m}^{2} \mathrm{~s}^{-1} \mathrm{~V}^{-1}\right)$ corresponds to the mobility of the counterions in the diffuse layer, the external part of 222 the electrical double layer (see Figure $1 \mathrm{~b})\left(\beta_{(+)}\left(\mathrm{Na}^{+}, 25^{\circ} \mathrm{C}\right)=5.2 \times 10^{-8} \mathrm{~m}^{2} \mathrm{~s}^{-1} \mathrm{~V}^{-1}\right), f(\approx 0.90)$ 223 denotes the fraction of counterions in the Stern layer (the inner part of the electrical double 224 layer), and the CEC denotes the cation exchange capacity (in $\mathrm{C} \mathrm{kg}^{-1}$ ) of the material.

225 Because of the large size of the grains in the channel, surface conductivity was found to 226 be negligible. For this specific application, we will neglect therefore surface conductivity and we 227 assume that $m$ and $n$ are the same (Revil, 2013, his Figure 18), and therefore the electrical 228 conductivity is given approximately by $\sigma=\theta^{m} \sigma_{w}$ from Eq. (16) where $m$ is the porosity 229 (cementation) exponent and $\theta=s_{w} \phi$ the water content.

\section{Laboratory Investigation}

\subsection{Material and Methods}

We have designed a laboratory experiment to test if we can monitor a heat pulse using the self-potential method. In addition, because the heat pulse is advected through a preferential flow 
235 path, the monitoring of the self-potential signals is used to visualize the preferential flow

236 channel. We use an experimental setup that is similar to the one described by Ikard et al (2012)

237 for a saline test called the SMART test (see Figure 1). Our tank is $0.46 \mathrm{~m}$ wide and $1.2 \mathrm{~m}$ long,

238 and consists of two rectangular reservoirs separated by a $0.99 \mathrm{~m}$ long sand body. Each reservoir

239 is $45.7 \mathrm{~cm}$ wide and $11.4 \mathrm{~cm}$ long, and separated from the sand body by a plastic membrane

240 square holes of $100 \mu \mathrm{m}$. We use two different sand units in the sandbox with a strong difference

241 in permeability. The coarse sand is the Unimin sand \#8 and the fine sand is the Unimin sand \#70

242 (see properties in Table 1). A central $15.2 \mathrm{~cm}$ wide high-permeability sand channel was flanked

243 on both sides by two $15.2 \mathrm{~cm}$ wide low-permeability fine-sand units (Figure1b). The electrical

244 conductivity of the tap water used for the experiment is $\sigma_{w}=(4.9 \pm 0.2) \times 10^{-2} \mathrm{~S} \mathrm{~m}^{-1}$ at $25^{\circ} \mathrm{C}$ (Table

245 2). The upstream and downstream reservoirs are instrumented with Aquistar CT2X submersible

246 SmartSensors. These sensors are used to measure temperature (accuracy and resolution equal to

$247+/-0.2^{\circ} \mathrm{C}$ and $0.1^{\circ} \mathrm{C}$, respectively) and pressure head (accuracy and resolution equal to $0.05 \%$ and

$2480.0034 \%$ of the measured value, respectively, Figure 1d). These measurements are performed

249 over time at a sampling frequency of $1 \mathrm{~Hz}$.

250 The sand was emplaced in the tank by first filling the tank with Unimin \#70 sand to a 251 depth of $39.4 \mathrm{~cm}$ and then excavating a rectangular channel to serve as a preferential flow 252 pathway. The \#70 sand was added in uniform, submerged layers to a standing water column.

253 Each newly added layer was sprinkled over the surface of the standing water and allowed to 254 settle out of suspension before it was combed and tamped to remove cavities and air bubbles and 255 mixed uniformly with the underlying sand. The tank then was drained and the preferential flow 256 channel was excavated from the partially saturated fine sand. The rectangular geometry of the 257 excavated channel was maintained during the excavation by stabilizing the side-walls with 
258 cardboard and incrementally backfilling the channel with dry layers of the coarse sand. Each

259 newly added layer of coarse sand was uniformly mixed with the underlying coarse sand. The

260 cardboard walls were removed incrementally during backfilling to allow the coarse sand to make

261 contact with and stabilize the fine sand walls, and to fill in the preferential flow channel. This

262 process helped to ensure a rectangular channel geometry. The entire sand body was then re-

263 saturated and drained again to allow each individual sand unit to settle and to stabilize the

264 contact boundary between the coarse channel and the flanking fine sand units. Water was

265 circulated through the sand by maintaining constant inflow and outflow rates in the upstream and

266 downstream reservoirs, respectively, with a series of hoses and valves.

267

268 3.2. Description of the Experiments

269 In order to distinguish between streaming and thermoelectric potential fluctuations, we

270 perform two pulse injections from the upstream reservoir. Each injection is equal in volume and

271 injected approximately at the same rate, but the temperature of the injected water was different,

272 above background temperature in Experiment \#1 and equal to background temperature in

273 Experiment \#2. The injection in Experiment \#1 consists of hot water (at boiling temperature),

274 and produced a total self-potential anomaly that is possibly a combined effect of the increased

275 pressure head in the reservoir (from the amount of water injected upstream) and the increased

276 temperature of the tracer. In addition, we will see below that if the temperature fluctuates at the

277 position of the electrodes, an apparent thermoelectric effect is generated because the electrodes

278 are not passive sensors with respect to temperature.

279 The boiling water is poured in the upstream reservoir, but, due to the dilution, the 280 temperature of the water in the upstream reservoir is only $3.6^{\circ} \mathrm{C}$ (Figure 2). The temperature of 
281 the second pulse is the same as the ambient temperature of the water in the steady-state flow 282 field, and therefore produced an anomaly that is independent of temperature and due solely to the 283 increased pressure head in the upstream reservoir. These injections are used to show that 284 temperature, in this experiment, is the main driver for the observed self-potential anomalies. We 285 will have to separate at osme point the intrinsic and apparent thermoelectric effects in 286 Experiment \#1. Hydraulic disturbances of same magnitude are created in Experiments \#1 and \#2, with the 288 same temporal characteristics. The mean hydraulic gradient between the two reservoirs is 289 maintained constant in Experiments \#1 and \#2 (the mean hydraulic gradient is 0.138 after the 290 injection of warm water in Experiment \#1 and 0.137 in Experiment \#2). The initial difference of 291 head is approximately $13.7 \mathrm{~cm}$ with a head of $37.4 \mathrm{~cm}$ in the upstream reservoir and $23.7 \mathrm{~cm}$ in 292 the downstream reservoir. The hydraulic and temperature data measured in the reservoirs are 293 shown in Figure 2. The time-lapse hydraulic gradient in the tank is shown in Figure 2a, while 294 Figure $2 \mathrm{~b}$ shows the temperature changes relative to the background after the injection of the 295 warm water. The evolution of the pressure heads in the two reservoirs shows only modest 296 changes (Figure 3).

297 During each injection, a volume of 2.15 L of water is poured into the upstream reservoir 298 at a rate of $0.215 \mathrm{~L} \mathrm{~s}^{-1}$, and the slug volume increased the hydraulic head in the upstream 299 reservoir by approximately $3.7 \mathrm{~cm}$. The sudden change in the hydraulic gradient due to the 300 hydraulic disturbance created by each injection occurs at $t=0 \mathrm{~s}$, after recording $120 \mathrm{~s}$ of 301 background data. After both injections the hydraulic gradient stabilized at approximately $t=600$ 302 s. 
The theoretical and observed velocities and residence times through the coarse channel

304 are in close agreement. For the coarse sand, with a hydraulic conductivity $K=1.52 \times 10^{-2} \mathrm{~m} \mathrm{~s}^{-1}$

305 (see Table 1), the mean Darcy velocity was computed from the mean hydraulic gradient as $\mathrm{u}=$ $3062.1 \times 10^{-3} \mathrm{~m} \mathrm{~s}^{-1}$. The mean linear velocity of the flowing water in the coarse sand channel is given 307 by $v=u \phi^{-1}$ (Dupuit-Forcheimer equation) where $\phi$ is the connected porosity yielding $v=5.4 \mathrm{x}$ $30810^{-3} \mathrm{~m} \mathrm{~s}^{-1}$. The residence time is given by $\tau=L / v(L=0.99 \mathrm{~m}$ is the length of the sand body) 309 and was determined to be 183 seconds (approximately 3 minutes) in the coarse sand channel. A 310 similar calculation for the fine sand yields a Darcy velocity of $u=1.9 \times 10^{-5} \mathrm{~m} / \mathrm{s}$, a linear 311 velocity $v=4.7 \times 10^{-5} \mathrm{~m} \mathrm{~s}^{-1}$, and therefore a corresponding residence time of 5.9 hours. The 312 conclusion is that the flow is mostly focused in the coarse-grained channel, which is acting 313 therefore as a preferential flow channel.

314 To verify this point and following the second slug injection, we introduced a red food dye 315 into the upstream reservoir to independently assess the residence time through the coarse 316 channel. The observed time for the breakthrough of the dye in the downstream reservoir 317 (visually observed) was 175 seconds, corresponding to a linear velocity of $v=5.7 \times 10^{-3} \mathrm{~m} \mathrm{~s}^{-1}$. 318 These values are very close to those estimated above from the head gradient and the 319 permeability. The residence time in the fine sand was not observed with the dye due to its low 320 permeability. The hydraulic conditions during the experiment are summarized in Table 3. The measurements of electric potential are recorded at the surface of the sand for a 322 duration of 1,500 s (25 minutes) using a network of electrode (Figure 1c). The voltages were 323 recorded with the BioSemi EEG system using 30 sintered $\mathrm{Ag}$-AgCl electrodes with integrated 324 amplifiers (Figure 1c and see Ikard et al., 2012 and Haas et al., 2013). The electrodes provided 325 low noise, low offset voltages, and stable DC performances. Specifications of the BioSemi EEG 
326 system can be found for instance in Crespy et al. (2008), Haas and Revil (2009), and Haas et al.

327 (2013) for laboratory applications (see also http://www.biosemi.com/). During the experiment

328 the electrodes were not in contact with the water table, which was approximately $2 \mathrm{~cm}$ below the

329 top surface of the tank in the vicinity of the upstream reservoir and increased in depth in a 330 downstream direction. All electrical potentials were measured relative to a reference electrode 331 denoted "REF" (see position in Figure 1c) at a frequency of $128 \mathrm{~Hz}$. The size of the electrodes 332 and the way they were emplaced in the sandbox is described in Ikard et al. (2012) and will not be 333 repeated here.

The data were processed prior to producing the time-lapse maps of the surface potential. A gain factor of 31.25 was removed from each electrode data stream. This gain is associated with the fact that all the electrodes are built with preamplifiers. The data were decimated by a factor

337 of 10. During the decimation process an 8th order Chebyshev type 1 low-pass filter was applied 338 to the data with a cutoff frequency of $0.8\left(f_{\mathrm{s}} / 2\right) / 10=5.12 \mathrm{~Hz}$, where $f_{\mathrm{s}}$ is the original sampling 339 frequency of the signals. The data were filtered in the forward and reverse directions to eliminate 340 all phase distortions. The smoothed signal was then re-sampled at a lower rate equal to $f_{\mathrm{s}} / 10=$ $341 \quad 12.8 \mathrm{~Hz}$.

Our electrodes are drifting slowly over time. Before the introduction of any perturbation 343 (e.g, the hot water), we record the signals on all the channels for a period of time (120 s in the 344 present case). We observed like in our previous publications with this instrument, that the drift of 345 the electrodes is linear with time. The $120 \mathrm{~s}$ of background data are therefore used to compute 346 and remove this linear drift from each electrode data stream. This method appears reliable to 347 remove, or at least considerably reduce the effect of the electrode drift on the self-potential 348 records. 
The processed, time-lapse potentials for selected electrodes are shown in Figure 4 for

350 both slug injections (Experiments \#1 and \#2). The data indicates the generation of clear self-

351 potential anomalies associated with the temperature effect. The processed, time-lapse records 352 corresponding to five electrodes over the channel are shown in Figure 5a and 5b (for the raw 353 data) for the hot water injection (Experiment \#1). After the data were processed, time-lapse maps 354 of the surface self-potential were produced in Surfer using a kriging approach based on 355 anisotropic semi-variograms. The data were fitted with an exponential semi-variogram with an 356 anisotropy ratio of 3.0 in the direction of the coarse channel (Figure 6). The maps were 357 referenced in time to the background electric potential distribution to show the relative changes 358 in the self-potential produced by the hydraulic and temperature disturbances that were produced 359 during the ambient and hot injections, respectively. The experiment was repeated three times and 360 the results were found to be reproducible to within $1 \mathrm{mV}$.

\section{3.3. Results}

The effect of the heat content contained in the hot water is evident in the electric potential 364 data and decreases the electric potential over the channel through time. Figure 4 shows processed 365 electric potential data in electrodes on the border of the channel and the fine sand (electrode 11) 366 as well as over the channel (electrodes 10). The influence of the injected heat pulse on the 367 potentials at electrode 11 is relatively weak compared to the electrodes over the channel, which 368 show anomalies with amplitudes in excess of $-5 \mathrm{mV}$ following the injection of the hot water in 369 Experiment \#1. The electric potential reaches a minimum of $-19.4 \mathrm{mV}$ in electrodes over the 370 channel following the injection of the hot water. 
We point out that the instrument used in this investigation (the Biosemi) is an excellent

372 instrument to measure short-lived disturbances (for instance hydromechanical disturbances

373 associated with fracking such as shown in Haas et al., 2013). When we want to follow long-term

374 disturbances (>30 minutes), at some point, we may have some problems to correct for the drift of

375 the electrodes, especially when the life expectation of the introduced disturbances is long.

376 The heat front moves through the channel as documented in this data by the sudden

377 decreases in electric potential in electrodes 10 (at $x=27.3 \mathrm{~cm}$ ), 16 (at $x=46.4 \mathrm{~cm}$ ), and 22 (at $x$

$378=65.4 \mathrm{~cm})($ see Figure $5 \mathrm{a})$. The effect of the heat front on the time-lapse electric potential is

379 observed at electrodes 10, 16, and 22, at the times $t \sim 140 \mathrm{~s}, t \sim 220 \mathrm{~s}$, and $t \sim 390 \mathrm{~s}$, respectively,

380 corresponding to a velocity of $1.9 \times 10^{-3} \mathrm{~m} \mathrm{~s}^{-1}$ between the upstream reservoir and electrode 22 for

381 the anomaly. These data therefore provide an estimate of the traveling velocity of the heat pulse.

382 This velocity compares well with the true velocity of the heat pulse obtained by the reservoir

383 temperature records (see data in Figure 2a). Indeed, the true velocity of the heat pulse given by

384 the temperature breakthrough curve in the downstream reservoir (which occurs at $t=668 \mathrm{~s}$ and

385 corresponding to a true velocity of the heat front of $1.5 \times 10^{-3} \mathrm{~m} \mathrm{~s}^{-1}$ ) is in agreement with the heat

386 velocity determined from electric potential data (Figure 5a).

387 The inferred traveling velocity of the heat pulse (both from the self-potential and 388 temperature data) is $67 \%$ smaller than the true ground water velocity in the preferential channel 389 (e.g., determined with the dye tracer test). The reduced velocity of the heat pulse is expected. It is 390 an effect of conduction of the heat into the surrounding materials, which will be apparent in the 391 numerical modeling results presented below in Section 5. Indeed, heat is a non-conservative 392 tracer and it is therefore expected that the velocity of the heat pulse is less than the velocity of 393 the flow field. 
The time-lapse self-potential snapshots at the top surface of the tank are shown in Figure 3956 in Experiment \#1. These maps show the change in electric potential relative to the background 396 and are shown for a $300 \mathrm{~s}$ interval between time $0 \mathrm{~s}$ and time $1500 \mathrm{~s}$. Maps corresponding to the 397 hot water injection are shown in Figure 6. In contrast to electrodes 10, 16 and 22, electrodes 4 398 and 28 over the permeable channel show positive changes in electric potentials in time-lapse, 399 when they are expected to show negative potentials due to the influence of temperature changes. 400 Indeed, the intrinsic thermoelectric coupling coefficient is expected to be negative for a silica 401 sand and the apparent thermoelectric coupling coefficient of the electrodes will be also negative 402 as explained later below. We have no explanation for these positive variations which are not 403 shown in the second experiment in which the same amount of water is injected in the upstream 404 reservoir without the presence of a heat pulse.

The first appearance of the negative anomaly in the channel appears at time $300 \mathrm{~s}$. The 406 anomaly grows in length in a downstream direction, as well as in amplitude, in time, and 407 accurately localizes the channel. When injecting water with the same temperature as the water 408 already in the tank, a change in electrical potential relative to the background is not observed up 409 to $900 \mathrm{~s}$. Thus, the pressure-head component of the observed anomaly is negligible.

\section{4. Numerical Modeling}

In this section we present a 3D numerical model of our laboratory experiment. Our goals

414 are (1) to show that injecting heat into a flow field results in an electric potential distribution at 415 the surface that can be used to localize preferential flow paths and (2) to determine the amplitude and sign of the thermoelectric coupling coefficient $C_{T}$. The calculations are performed with the 
417 finite element approach in Comsol Multiphysics v4.4. To be sure that the results are mesh-

418 independent, we start the computations with a coarse mesh and we reduce the size of the mesh

419 until the calculation becomes mesh-independent.

420 We first performed a steady-state simulation of the velocity field using the equations

421 given in Section 2.1. Then, we compute the resulting streaming potential response from the

422 equations given in Section 2.3 in order to understand the magnitude and polarity of the

423 background self-potential signals. Finally, we performed a transient simulation of experiments

$424 \# 1$ and \#2 to compute the time-dependent velocity distribution and the associated electric

425 potential distribution in the tank that is caused by the hydraulic and thermal disturbances

426 associated with the injections. For the simulation of experiment \#1 (injection of the hot water),

427 we also compute the associated temperature distribution through time. For each simulation we

428 model the potential field which is coupled to the velocity and temperature distributions through

429 the equations given in Sections 2.2 and 2.3.

430 For the steady-state background simulation, only the velocity field and associated

431 potential distribution are simulated. The boundary conditions for this simulation remain

432 unchanged for the transient simulation, with the exception that the mean hydraulic gradient

433 boundary applied to the Richards equations is replaced with the transient hydraulic gradient

434 shown in Figure 2a. For the modeling of Experiment \#1, the velocity field and temperature

435 distribution were simulated through time, and the electric potential distribution was simulated

436 using snapshot solutions for the velocity and temperature distribution at a few time steps.

To solve for the velocity field in steady-state conditions, the mean hydraulic gradient was

438 applied to the tank by specifying the mean hydraulic heads in the upstream and downstream

439 reservoirs. Zero-flux hydraulic boundary conditions were applied at all remaining boundaries of 
440 the tank. To compute the electric field an electric insulation boundary was applied at the tank

441 surface, distributed impedance boundaries were applied in each reservoir, and an electric ground

442 boundary was applied at all remaining boundaries. Distributed impedance boundaries were

443 assigned an electric conductivity equal to the conductivity of the reservoir water and a thickness

444 equal to the vertical dimension of water column in the reservoir.

445 To compute the transient temperature distribution, the temperature in the upstream 446 reservoir was specified by the time-lapse record displayed in Figure 2b. The temperature was 447 also specified to be room temperature on the sidewalls and bottom of the tank. A thermal 448 insulation boundary was applied to the tank surface to account for the large contrast in thermal 449 conductivity between water and air, and an open boundary condition was applied in the 450 downstream reservoir.

\subsection{Steady-state (background) Simulation}

As explained above, we first simulated the steady-state velocity field and saturation 454 distribution, as well as the background streaming potential to observe the magnitude and polarity 455 and orientation of the electric potential anomaly due to steady preferential flow through the 456 coarse channel. Figure 7 a shows the simulated saturation. We observe that the coarse channel is 457 predominantly unsaturated at the downstream face above the water level of the downstream 458 reservoir. At the opposite, the water content in the fine sand is high in the vadose zone due to the 459 strong capillary effects associated with the smaller size of the pores. The longitudinal saturation 460 profile between the upstream and downstream reservoirs is parabolic, and varies between $s_{e}=$ 4610.55 to $s_{e} \sim 0.1$ in the unsaturated portion of the channel. The fine sand is predominantly 462 saturated and the effective saturation varies from $s_{e}=1$ to $s_{e} \sim 0.75$ at the downstream end 463 (Figure 7a). 
Flow is primarily contained within the coarse channel although some flow does occur

465

466

467

468

469

470

471

472

473

474

475 476 to the background. the thermal anomaly).

through the fine sand at a much slower velocity. The background streaming potential distribution consists of a large anomaly centered over the channel and extending partially into the flanking fine sand units (Figure 7). The polarity of the anomaly over the channel is negative (as expected see discussion in Ikard et al., 2012) and the amplitude of the anomaly is comprised between -4 $\mathrm{mV}$ and $-7 \mathrm{mV}$ over the permeable channel. Unfortunately, it is not possible to check this prediction with our data since the absolute differences of electrical potential from electrode to electrode are unknown (this is why we offset all the potentials to zero before the introduction of

Transient simulations were performed for Experiments \#1 and \#2 to evaluate the evolution of the time-lapse electric potential anomaly associated with each injection. All the figures show the changes in the respective fields (i.e., electric potential and temperature) relative

\subsection{Transient Simulation of Experiment \#2}

The simulation results for experiment \#2 are shown in Figure 8, and the result for the 479 simulation of Experiment \#1 is displayed in Figures 9 to 12. The maximum electric potential 480 simulated for Experiment \#2 is in the range of $0.25 \mathrm{mV}$ to $0.3 \mathrm{mV}$ (Figures $8 \mathrm{a}$ and $8 \mathrm{~b}$ ), and 481 occurred mostly on the downstream face as water was forced out of the downstream end of the 482 tank. The minimum electric potential of $\sim-0.15 \mathrm{mV}$ that was produced in the simulation of 483 Experiment \#2 occurred on the upstream face of the tank (Figure 8b) as water was forced into the 484 channel at the upstream end. The electric potential simulated at the surface of the tank is much 485 smaller (on the order of $-0.05 \mathrm{mV}$ at the upstream end to $+0.015 \mathrm{mV}$ at the downstream end of 
487 simulation of Experiment \#2 (injection of the water at the background temperature) confirms the 488 very small (positive) self-potential anomaly over the permeable channel observed in the 489 laboratory data (see Section 3).

\subsection{Transient Simulation of Experiment \#1}

492 Model simulations for the injection of hot water (Experiment \#1) are shown in Figures 9

to 12. Figure 9 shows time-lapse snapshots of the surface of the tank, and the temperature distribution through time. Time $0(t=0 \mathrm{~s})$ corresponds to the background condition when there is no relative change in temperature in the tank. Beyond time 0 , heat introduced by the hot water injection can be seen entering the flow field and migrating in a downstream direction through the flanking fine sand units (Figure 9). The spreading of the heat is shown by the reduction of over time. For instance, in the late-time snapshot shown at time 5, the temperature appears to be distributed throughout the entire sand body and is approximately between $0.5^{\circ} \mathrm{C}$ and $1.5^{\circ} \mathrm{C}$. The peak temperature observed over the channel in the modeling results is approximately $3.5{ }^{\circ} \mathrm{C}$ 503 inside of the channel, and $2.7{ }^{\circ} \mathrm{C}$ over the channel at the surface of the tank.

505 Figure 10 shows a set of snapshots of the growth of the electric potential anomaly at the tank surface. This self-potential anomaly can be seen growing in time at the surface, predominantly

507 over the channel where the surface temperature is the greatest, and is correlated with the growth 508 of the temperature anomaly shown in Figure 9 at the surface of the tank. The polarity of the 509 anomaly is strongly negative, and the peak amplitude achieved in the modeling results is 
510 approximately $-13 \mathrm{mV}$, much greater than the peak amplitude observed in the numerical

511 simulation of Experiment \#2. The peak amplitude of the anomaly is negative over the channel.

512 The position of the modeled self-potential anomaly is consistent with the underlying position of

513 the permeable channel. This observation illustrates the key influence of the subsurface

514 temperature gradient on the electric potential observed at the surface. The simulation of

515 Experiment \#1 shows an anomaly in the form of a transient peak in potential (Figures 10 and 11).

516 The white vectors in Figure 11 represent the velocity field through the channel. Heat conduction

517 from the channel into the surrounding sands implies a slight increase in temperature just above

518 the water table and in the banks of the channel (Figure 11a).

519

The dependence of the subsurface temperature, and more specifically the influence of the

520 subsurface temperature gradient upon the electric potential anomaly at the top surface of the tank

521 surface is noticeable (Figure 12). The peak of the anomaly is centered primarily over the

522 permeable channel where the peak temperature amplitude is observed. The increase in

523 temperature along Profile 1 outside of the channel boundaries is a result of the model simulating

524 heat conduction from the permeable channel into the fine sands. Figure $12 b$ shows the

525 corresponding growth of the electric potential anomaly through time, and the peak amplitude is

526 also centered over the channel. Both the temperature and electric potential anomalies observed

527 along Profile 1 grow in time as the heat in the channel approaches the position of Profile 1, and 528 then decrease in magnitude back towards the background as the heat pulse in the channel passes

529 Profile 1. The modeled in situ temperature changes along Profile 1 follows a linear trend with the 530 numerically modeled changes in electrical potential at the surface of the tank (Figure 12c). The

531 obtained relationship is strongly linear, with a regression coefficient of $R^{2}=0.999$, indicating a

532 strong dependence of the electric potential measured at the surface of the tank on the in situ 
533 temperature. The slope of the relationship is equal to $-4.9 \mathrm{mV}^{\circ} \mathrm{C}^{-1}$, which is nearly equal to the

534 intrinsic thermoelectric coupling coefficient $C_{T}$ used for the simulation $\left(C_{T}=-5 \mathrm{mV}^{\circ} \mathrm{C}^{-1}\right)$. The

535 strongly linear relationship between temperature and electric potentials shown in Figure 12c,

536 with slope roughly equal to the intrinsic thermo-electric coupling coefficient, indicates that there

537 is indeed a strong temperature-dependence of the electric potential that is being modeled at the 538 tank surface, which corroborates the experimental laboratory observations. These values are 539 compared with laboratory data in the next section.

540

541 5. Discussion

542

We discuss now the origin of the temperature driven self-potential signals we observed in

543 our experiment (see Figure 13 for Profile 1). We first discuss the amplitude of the intrinsic 544 thermoelectric effect in the literature, then we discuss the amplitude of the temperature effect on 545 the streaming potential coupling coefficient, and finally, we discuss the effect of temperature on 546 the potential of the electrodes themselves.

\section{$548 \quad$ 5.1. Intrinsic thermoelectric effect}

The intrinsic thermoelectric effect discussed in Section 2.3 above refers to the generation

550 of a source current density in a porous body in response to a thermal gradient. The conversion of 551 heat to electricity is usually called the Peltier-Seebeck effect and was pioneered by the Estonian 552 physicist Thomas Seebeck in 1821 (e.g., Chambers, 1977). It was later explained in more detail 553 by the French physicist Jean Peltier (see Chambers, 1977). In porous media, little is known about 554 this effect and its polarity and magnitude. Laboratory measurements were reported by Marshall 
555

556

557

558

559

560

561

562

563

564

565

566

567

568

569

570

571

572

573

574

575

576

577 and Madden (1959), Nourbehecht (1963), Dorfman et al. (1977), Corwin and Hoover (1979), Fitterman and Corwin (1982), and recently by Leinov et al. (2010).

As discussed by Revil (1999), there is a crucial issue with the existing laboratory measurements performed before the eighties: the authors never mentioned if they corrected their data for the temperature dependence of the electrodes and non-polarizing electrodes are known to be quite sensitive to temperature creating therefore an apparent thermoelectric effect. Around $T_{0}=25^{\circ} \mathrm{C}$, the temperature dependence of the commonly used electrodes is $+0.20 \mathrm{mV}^{\circ} \mathrm{C}^{-1}$ for the $\mathrm{Pb} / \mathrm{PbCl}_{2}$ electrodes (Petiau, 2000), $+0.7 \mathrm{mV}{ }^{\circ} \mathrm{C}^{-1}$ to $+0.9 \mathrm{mV}{ }^{\circ} \mathrm{C}^{-1}$ for the $\mathrm{Cu} / \mathrm{CuSO}_{4}$ electrodes (Antelman, 1982; Clennel Palmer and King, 2004), and -0.43 to $-0.73 \mathrm{mV}{ }^{\circ} \mathrm{C}^{-1}$ for the $\mathrm{Ag} / \mathrm{AgCl}$ electrodes (Antelman, 1982; Rieger, 1994). We believe therefore that the existing laboratory measurements (with the recent exception of Leinov et al. 2010) are not necessarily reliable. Revil et al. (2013) performed a thermoelectric measurement keeping the electrodes outside the area characterized by a change in temperature. They obtained a value of the thermoelectric coupling coefficient of $-0.5 \mathrm{mV}^{\circ} \mathrm{C}^{-1}$. Marshall and Madden (1959), Revil (1999), and Leinov et al. (2010) modelled the thermoelectric effect from the temperature dependence of the chemical potential of the ions contained in the pore water of the porous material.

In all cases, the thermoelectric coefficient seems generally comprised between $-0.5 \mathrm{mV}$ ${ }^{\circ} \mathrm{C}^{-1}$ to $+1.5 \mathrm{mV}{ }^{\circ} \mathrm{C}^{-1}$ and seems to be controlled by the composition and salinity of the pore water. If we consider a value of the intrinsic thermoelectric coupling coefficient of $-0.5 \mathrm{mV}^{\circ} \mathrm{C}^{-1}$, a temperature fluctuation of $4{ }^{\circ} \mathrm{C}$ should be responsible for a negative self-potential anomaly of $2 \mathrm{mV}$. There is therefore a discrepancy between the value of the intrinsic thermoelectric coupling coefficient required to explain the observed negative self-potential anomaly ( -4 to $-6 \mathrm{mV}$ range in reference to the observed anomaly or the value of the thermo coupling coefficient, Figure 13) 
578 and that obtained from the observed self-potential anomaly. We look for two possible additional

579 contributions in the next sections.

\subsection{Influence of Temperature on the Streaming Potential}

582

We investigate in this section a different possibility, which is given by the fact that the

583 streaming potential coupling coefficient is also temperature dependent. Somasundaran and 584 Kulkani (1973), Ishido and Mizutani (1981), and Revil et al. (1999b) discussed the effect of 585 temperature on the streaming potential coupling coefficient. We performed an analysis of the 586 temperature dependence of this coefficient in Appendix A. We show that the dependence of the 587 streaming potential coupling coefficient is the same as the temperature dependence of the

588 effective charge density $\hat{Q}_{V}(T)$. Using the data shown in Figure 14 for quartz, we obtain $\alpha_{Q}=$ $5890.021{ }^{\circ} \mathrm{C}^{-1}$. Therefore a variation of $4{ }^{\circ} \mathrm{C}$ corresponds to a variation of $8.4 \%$ of the streaming 590 potential coupling coefficient. It also follows that an increase in temperature should make the 591 self-potential anomaly in the channel more negative. We perform a simulation of the self592 potential signals associated with the temperature dependence of the streaming potential coupling 593 coefficient (Figure 15). A very small negative self-potential anomaly is produced over the 594 channel. This is consistent with the polarity of the self-potential anomaly observed in our 595 experiment but the magnitude of this anomaly is far too small $(0.1 \mathrm{mV})$. We consider now that 596 the pre-existing self-potential anomaly over the channel is $-7 \mathrm{mV}$ (see Section 4.1. above). 597 Therefore a $8.4 \%$ variation of the self-potential signals creates another $-0.6 \mathrm{mV}$ of self-potential 598 anomaly at most. So we still have problems to explain the observed self-potential anomaly. 
One effect that has not been accounted for so far is the effect of temperature on the 602 potential of the electrodes. Indeed, $\mathrm{Ag} / \mathrm{AgCl}$ electrodes are not inert sensors with respect to 603 temperature. In other words, their inner potential depends on temperature. In our case, we use the 604 Biosemi Ag/AgCl electrodes. In 0.1 N KCl, Antelman (1989) reports an apparent thermoelectric 605 coupling effect for the $\mathrm{Ag} / \mathrm{AgCl}$ electrodes of $-0.43 \mathrm{mV} \mathrm{K}^{-1}$. At higher salinities, Rieger (1994) 606 reports a value of $-0.73 \mathrm{mV} \mathrm{K}^{-1}$. For Profile \#1 at $900 \mathrm{~s}$, the temperature reaches at the top 607 surface of the tank is $\sim 2.5{ }^{\circ} \mathrm{C}$ (see Figures 9 and 12a), generating therefore an apparent self608 potential anomaly of -1 to $-2 \mathrm{mV}$.

In Figure 13, we compare the observed self-potential anomalies to our model. To explain 610 the data, we need a total coupling coefficient of $-2.5 \mathrm{mV} \mathrm{K}^{-1}$ and $-1.0 \mathrm{mV} \mathrm{K}^{-1}$. However -0.4 to $6110.7 \mathrm{mV} \mathrm{K}^{-1}$ are due to the temperature dependence of the potential of the electrodes with the 612 temperature. We can say therefore that the intrinsic thermoelectric coupling coefficient of the 613 sand is probably comprised between -0.3 to $-1.8 \mathrm{mV} \mathrm{K}^{-1}$.

\subsection{Comparison with a salt tracer test}

Ikard et al. (2013) performed a salt tracer test with a similar tank and the same sand.

617 During such salt tracer tests, the observed self-potential anomaly was due to the effect of the 618 salinity upon the streaming potential and the diffusion potential associated with the salinity 619 gradient. The observed self-potential variation was on the order of $+5 \mathrm{mV}$, which can be compared to the $-12 \mathrm{mV}$ anomaly observed in the present experiment. The biggest contributor to

621 the self-potential anomaly was due to the salinity effect on the streaming potential. In the present 622 case, we have shown that the temperature effect on the streaming potential seems negligible with 623 respect to the thermoelectric effect. It could be interesting to inject a salty heat pulse. A 
624 conservative salt would travel faster than the heat itself and therefore we should be able to see a 625 dipolar anomaly traveling in the tank.

626

\section{6. Conclusions}

628

629

630

631

632

633

634

635

636

637 spurious effect.

638

639

640

641

642

643

644 per ${ }^{\circ} \mathrm{C}$. The lowest values are compatible with the recent study of Revil et al. (2013), who

645 obtained a value of the intrinsic thermoelectric coupling coefficient of $-0.5 \mathrm{mV}^{\circ} \mathrm{C}^{-1}$ 
(5) The effect of temperature tends to increase the amplitude of the streaming potential 647 coupling coefficient producing also a negative self-potential anomaly. However this negative 648 self-potential anomaly seems modest (not more than $1 \mathrm{mV}$ for the temperature change occurring 649 in the tank).

650 Future work will include applying this method at a field site as well as performing 651 additional laboratory investigations aimed at quantifying the magnitude, polarity, and 652 background physics of the intrinsic thermoelectric coupling coefficient for saturated porous 653 materials with variable textural properties (grain size distributions, porosity, and permeability) 654 and pore water composition on the thermoelectric coupling coefficient.

655

656 Acknowledgements. We thank the US. Department of Energy DOE (Geothermal Technology 657 Advancement for Rapid Development of Resources in the U.S., GEODE, award \#DE658 EE0005513 to A. Revil and M. Batzle) and NSF (PIRE). We thank the Associate Editor, S. 659 Huisman, J. Renner, and two anonymous referees for their very constructive comments. 


\section{References}

662 Abaza, M.M., Clyde, C.G., 1969. Evaluation of the rate of flow through porous media using 663 electrokinetic phenomena. Water Resources Research 5(2), 470-483.

AlSaigh, N.H., Mohammed, Z.S., Dahham, M.S., 1994. Detection of water leakage from dams by selfpotential method. Engineering Geology 37 (2), 115-121.

Antelman, M.S., 1989. The encyclopedia of chemical electrode potentials, Plenum Press, New York.

Archie, G.E., 1942. The electrical resistivity $\log$ as an aid in determining some reservoir characteristics. Transactions of the American Institute of Mining, Metallurgical and Petroleum Engineers 146, 54-62.

Bolève A., Revil, A., Janod, F., Mattiuzzo, J. L., Jardani, A., 2007. Forward modeling and validation of a new formulation to compute self-potential signals associated with ground water flow. Hydrology and Earth Systems Science 11, 1-11.

Bolève, A., Revil, A., Janod, F., Mattiuzzo, J. L., Fry, J.-J., 2009. Preferential fluid flow pathways in embankment dams imaged by self-potential tomography. Near Surface Geophysics 7 (5), 447-462.

Bolève, A., Janod, F., Revil, A., Lafon A., Fry, J., 2011. Localization and quantification of leakages in dams using time-lapse self-potential measurements associated with salt tracer injection. Journal of Hydrology 403, 242-252.

Bolève A., Vandemeulebrouck, J., Grangeon, J., 2012. Dyke leakage localization and hydraulic permeability estimation through self-potential and hydro-acoustic measurements: Self-potential 'abacus' diagram for hydraulic permeability estimation and uncertainty computation. Journal of Applied Geophysics 86, 17-28 
684 Chambers, R. G., 1977. Thermoelectric effects and contact potentials. Physics Education 12(6), 685 374-380.

686 Clennel Palmer, A., King R.A., 2004. Subsea Pipeline Engineering, PennWell Books, 570 pp.

687 Corwin, R.F., 1985. The self-potential method and its engineering applications - an overview. 688 Geophysics 50, 282-282.

689 Corwin, R. F., Hoover, D. B., 1979. The self-potential method in geothermal exploration. 690 Geophysics 14, 226-245.

691 Crespy, A., Revil, A., Linde, N., Byrdina, S., Jardani, A., Bolève, A., Henry, P., 2008. Detection 692 and localization of hydromechanical disturbances in a sandbox using the self-potential 693 method. Journal of Geophysical Research 113, B01205, doi: 10.1029/2007JB005042.

694 Dorfman, M. H., Oskay, M.M., Gaddis M.P. 1977. Self-potential profiling. A new technique for 695 determination of heat movement in a thermal oil recovery flood. SPE 6790, 52nd Annual 696 Conference Preceedings of the Society of Petroleum Engineers of the AIME, Denver 697 Colorado, October 1977.

698

Fitterman, D.V., Corwin R.F., 1982. Inversion of self-potential data from the Cerro Prieto 699 geothermal field, Mexico. Geophysics 47, 938-945.

700

Gex, P., 1980. Electrofiltration phenomena associated with several dam sites. Bulletin of the 701 Society Vaud Science and Nature 357 (75), 39-50.

702 Haas, A., Revil, A., 2009. Electrical signature of pore scale displacements. Water Resources 703 Research 45, W10202, doi:10.1029/2009WR008160.

704 Haas, A. K., Revil, A., Karaoulis, M., Frash, L., Hampton, J., Gutierrez, M., Mooney, M., 2013. 705 Electrical potential source localization reveals a borehole leak during hydraulic fracturing. 706 Geophysics 78 (2), D93-D113, 10.1190/GEO2012-0388.1. 
707

708

709

710

711

712

713

714

715

716

717

718

719

720

721

722

723

724

725

726

727

728

729

730

Hermans, T., Vandenbohede A., Lebbe, L., Nguyen, F., 2012, A shallow geothermal experiment in a sandy aquifer monitored using electric resistivity tomography. Geophysics 77 (1), B11-B21, doi: 10.1190/GEO2011-0199.1

Ikard, S. J., Revil, A., Jardani, A., Woodruff, W. F., Parekh, M., Mooney, M., 2012. Saline pulse test monitoring with the self-potential method to non-intrusively determine the velocity of the pore water in leaking areas of earth dams and embankments. Water Resources Research 48, 1-17.

Ishido, T., Mizutani, H., 1981, Experimental and theoretical basis of electrokinetic phenomena in rock-water systems and its applications to geophysics. J. Geophys. Res. 86, 1763-1775.

Jardani, A., Revil, A., Bolève, A., Dupont, J.P., Barrash, W., Malama, B. 2007. Tomography of groundwater flow from self-potential (SP) data. Geophysical Research Letters 34, L24403, doi:10.1029/2007GL031907.

Jardani, A., Revil A., Dupont J.P., 2013. Stochastic joint inversion of hydrogeophysical data for salt tracer test monitoring and hydraulic conductivity imaging. Advances in Water Resources 52, 62-77, doi: 10.1016/j.advwatres.2012.08.005.

Leinov, E., Vinogradov, J. Jackson, M. D., 2010. Salinity dependence of the thermoelectric coupling coefficient in brine-saturated sandstones. Geophysical Research Letters (37), L23308, doi:10.1029/2010GL045379.

Luo, M., Wood, J.R., Cathles, L.M., 1994. Prediction of thermal conductivity in reservoir rocks using fabric theory. Journal of Applied Geophysics 32, 321-334.

Maineult, A., Bernabé, Y., Ackerer, P., 2005. Detection of advected concentration and pH fronts from self-potential measurements, Journal of Geophysical Research 110, B11205.

Maineult, A., Bernabé, Y., Ackerer, P., 2006. Detection of advected, reacting redox fronts from self-potential measurements. Journal of Contaminant Hydrology 86, 32-52. 
731 Marshall, D. J., and Madden, T. R., 1959. Induced polarization: A study of its causes. $732 \quad$ Geophysics 24, 790-816.

733 Martínez-Pagán P., Jardani, A., Revil, A., Haas, A., 2010. Self-potential monitoring of a salt 734 plume. Geophysics, 75 (4), WA17-WA25, doi: 10.1190/1.3475533.

735 Moore, J.R., Bolève, A., Sanders, J.W., Glaser, S.D., 2011. Self-potential investigation of 736 moraine dam seepage. Journal of Applied Geophysics (74), 277-286.

737 Mualem, Y., 1986. Hydraulic conductivity of unsaturated soils: prediction and formulas. In 738 739 Methods of Soil Analysis, Edited by A. Klute, American Society of Agronomy, Madison, Wisconsin $9(1), 799-823$.

Naudet, V., Revil, A., Bottero, J.Y. 2003. Relationship between self-potential (SP) signals and redox conditions in contaminated groundwater. Geophysical Research Letters 30 (21).

742 Naudet, V., Revil, A., Rizzo, E., Bottero, J.Y., Begassat, P., 2004. Groundwater redox 743 744 conditions and conductivity in a contaminant plume from geoelectrical investigations. Hydrology and Earth Systems Sciences 8 (1) 8-24.

745 746

747

748

749

750 751

752 753
Nourbehecht, B., 1963. Irreversible thermodynamics effects in inhomogeneous media and their applications in certain geoelectric problems. Ph.D. thesis, Mass Inst. of Technol., Cambridge, Mass.

Panthulu, T.V., Krishnaiah, C., Shirke, J.M., 2001. Detection of seepage paths in earth dams using self-potential and electrical resistivity methods. Engineering Geology 59, 281-295.

Petiau, G., 2000. Second generation of lead-lead chloride electrodes for geophysical applications. Pure Appl. Geophys. 157, 357-382.

Revil, A., Pezard, P.A., Glover, P.W.J., 1999a. Glover, Streaming potential in porous media. 1. Theory of the zeta-potential. Journal of Geophysical Research 104(B9), 20,021-20,031. 
754 Revil, A., Schwaeger, H., Cathles, L.M., Manhardt, P., 1999b. Streaming potential in porous

755

756

757

758

759

760

761

762

763

764

765

766

767

768

769

770

771

772

773

774

media. 2. Theory and application to geothermal systems, Journal of Geophysical Research, 104(B9), 20,033-20,048.

Revil, A., 1999. Ionic diffusivity, electrical conductivity, membrane and thermoelectric potentials in colloids and granular porous media: A unified model. Journal of Colloid and Interface Science 212, 503-522.

Revil, A., Leroy, P., 2001. Hydroelectric coupling in a clayey material. Geophysical Research Letters 28 (8) 1643-1646.

Revil, A., Hermitte, D., Voltz, M., Moussa, R., Lacas, J., Bourrié, G., Trolard, F., 2002. Selfpotential signals associated with variations of the hydraulic head during an infiltration experiment. Geophysical Research Letters 29 (7) 1-10.

Revil, A., Naudet, V., Nouzaret, J., Pessel, M., 2003. Principles of electrography applied to selfpotential electrokinetic sources and hydrogeological applications. Water Resources Research 39 (5).

Revil, A., Linde, N., 2006. Chemico-electromechanical coupling in microporous media. Journal of Colloid and Interface Science 302, 682-694.

Revil, A., 2007. Thermodynamics of transport of ions and water in charged and deformable porous media. Journal of Colloid and Interface Science 307 (1), 254-264.

Revil, A., Karaoulis, M., Srivastava, S., Byrdina, S., 2013. Thermoelectric self-potential and resistivity data localize the burning front of underground coal fires. Geophysics 78 (5), B259-B273. 
775 Revil, A., Mahardika, H., 2013. Coupled hydromechanical and electromagnetic disturbances in

776

777

778

779

780

781

782

783

784

785

786

787

788

789

790

791

792

793

794

795

796

797

unsaturated clayey materials. Water Resources Research, 49 (2), 744-766, doi:10.1002/wrcr.20092.

Revil, A., 2013. Effective conductivity and permittivity of unsaturated porous materials in the frequency range $1 \mathrm{mHz}-1 \mathrm{GHz}$. Water Resources Research 49, 306-327, doi:10.1029/2012WR012700.

Richards, L. A., 1931. Capillary conduction of liquids through porous media. Physics 1, 318333.

Rieger, P.H., 1994. Electrochemistry, Springer, 483 pages.

Rozycki, A., Fonticiella, J. M. R., Cuadra, A., 2006. Detection and evaluation of horizontal fractures in earth dams using self-potential method. Engineering Geology 82, 145-153.

Sakaki, T., 2009. Physical, hydraulic, and thermal properties of silica sands for laboratory experiments. Internal Report, Center for Experimental Study of Subsurface Environmental Processes (CESEP), Colorado School of Mines, Golden, Colorado.

Salvatore, S., De Biase, M., 2013. Estimation of longitudinal dispersivity in a porous medium using self-potential signals. Journal of Hydrology 505, 163-171.

Sheffer, M.R., Howie, J.A., 2001. Imaging subsurface seepage conditions through the modeling of streaming potential. Proceedings of $54^{\text {th }}$ Canadian Geotechnical Conference, Calgary, 1094-1101.

Sill, W.R., 1983. Self-potential modeling from primary flows. Geophysics 48 (1), 76-86.

Song, S. H., Song, Y., Kwon, B.D., 2005. Application of hydrogeological and geophysical methods to delineate leakage pathways in an earth fill dam. Exploration Geophysics 36, 92-96. 
798 Somasundaran, P., Kulkani, R.D., 1973. A new streaming potential apparatus and study of 799 temperature effects using it. J. Colloid Interface Sci. 45, 591-600.

800 van Genuchten, M.T., 1980. A closed-form equation for predicting the hydraulic conductivity of $801 \quad$ unsaturated soils. Soil Sci. Soc. 44, 892-898.

802 


\section{Tables}

841 Table 1. Properties of the two sands used in the experiment and modeling.

\begin{tabular}{|l|l|l|}
\hline Properties & $\begin{array}{l}\text { Coarse sand } \\
(\text { Channel, \#08) }\end{array}$ & $\begin{array}{l}\text { Fine sand } \\
(\text { Banks, \#70) }\end{array}$ \\
\hline Mean grain diameter $d_{50}(\mathrm{~m})(1)$ & $1.4 \times 10^{-3}$ & $2.0 \times 10^{-4}$ \\
Porosity $\phi(-)(1)$ & 0.396 & 0.413 \\
Formation factor $F(-)$ & 3.33 & 3.16 \\
Cementation exponent, $m(-)$ & 1.3 & 1.3 \\
Hydraulic conductivity $K\left(\mathrm{~m} \mathrm{~s}^{-1}\right)(1)$ & $1.5 \times 10^{-2}$ & $1.4 \times 10^{-4}$ \\
Residual water content, $\theta_{\mathrm{r}}(-)(1)$ & 0.006 & 0.037 \\
Saturated water content, $\theta_{\mathrm{s}}(-)(1)$ & 0.396 & 0.413 \\
van Genuchten parameter, $\alpha\left(\mathrm{m}^{-1}\right)(1)$ & 3.72 & 22.6 \\
van Genuchten parameter, $n(-)(1)$ & 6.20 & 5.28 \\
Bulk density, $\rho\left(\mathrm{kg} \mathrm{m}^{-3}\right)$ & 1600 & 1560 \\
Charge density $\hat{Q}_{V}\left(\mathrm{C} \mathrm{m} \mathrm{m}^{-3}\right)(2)$ & $1.85 \times 10^{-4}$ & 0.417 \\
Conductivity, $\sigma\left(\mathrm{S} \mathrm{m}^{-1}\right)(3)$ & $1.47 \times 10^{-2}$ & $1.55 \times 10^{-2}$ \\
Thermal conductivity solid, $\lambda_{s}\left(\mathrm{~W} \mathrm{~m}^{-1} \mathrm{~K}^{-1}\right)$ & 8.5 & 8.5 \\
Specific heat capacity, $C\left(\mathrm{~J} \mathrm{~kg}^{-1} \mathrm{~K}^{-1}\right)$ & 730 & 730 \\
\hline
\end{tabular}

843 (1) From Sakaki (2009).

844 (2) Using $\log _{10} \bar{Q}_{V}=-9.23-0.82 \log _{10} k, k$ is the permeability in $\mathrm{m}^{2}$ (Revil and Jardani, 2010)

845 (3) Using $\sigma=\sigma_{w} / F$ with $\sigma_{w}=(4.9 \pm 0.2) \times 10^{-2} \mathrm{~S} \mathrm{~m}^{-1}$ at $25^{\circ} \mathrm{C}$.

846 (4) Thermal properties of water $C_{w}=4181.3 \mathrm{~J} \mathrm{~kg}^{-1} \mathrm{~K}^{-1}$ and $\lambda_{w}=0.58 \mathrm{~W} \mathrm{~m}^{-1} \mathrm{~K}^{-1}$. 
848 Table 2. Composition of the tap water corresponding to a TDS of $245 \mathrm{ppm}\left(\sim 5 \times 10^{-2} \mathrm{~S} \mathrm{~m}^{-1}\right.$ at $\left.84925^{\circ} \mathrm{C}\right) \cdot \mathrm{pH}=8.4$. At this conductivity, the streaming potential coupling coefficient is typically $850 \quad 5.0 \mathrm{mV} \mathrm{m}^{-1}$.

\begin{tabular}{|c|c|}
\hline Component & $\left.\begin{array}{c}\text { Concentration } \\
(\mathrm{mMol} \mathrm{L}\end{array}{ }^{-1}\right)$ \\
\hline $\mathrm{Ca}^{2+}$ & 0.95 \\
$\mathrm{~K}^{+}$ & 0.09 \\
$\mathrm{Na}^{+}$ & 1.44 \\
$\mathrm{Cl}^{-}$ & 1.30 \\
$\mathrm{SO}_{4}{ }^{2-}$ & 0.82 \\
$\mathrm{HCO}_{3}{ }^{-}$ & 0.75 \\
\hline
\end{tabular}

851

852

853 
854 Table 3. Summary of hydraulic conditions during each slug injection

\begin{tabular}{|l|c|c|}
\hline Properties & $\begin{array}{c}\text { Experiment \#1 } \\
\text { (warm water) }\end{array}$ & $\begin{array}{c}\text { Experiment \#2 } \\
\text { (ambient temperature) }\end{array}$ \\
\hline Volume of injected water (Liter, $\mathrm{L})$ & 2.15 & 2.15 \\
Injection rate $\left(\mathrm{L} \mathrm{s}^{-1}\right)$ & 0.215 & 0.215 \\
Mean hydraulic gradient $(-)$ & 0.137 & 0.138 \\
Mean Darcy velocity in channel $\left(\mathrm{m} \mathrm{s}^{-1}\right)$ & $2.1 \times 10^{-3}$ & $2.1 \times 10^{-3}$ \\
Linear Velocity in channel $\left(\mathrm{m} \mathrm{s}^{-1}\right)$ & $5.4 \times 10^{-3}$ & $5.4 \times 10^{-3}$ \\
Dye tracer velocity $\left(\mathrm{m} \mathrm{s}^{-1}\right)$ & $5.7 \times 10^{-3}$ & $5.7 \times 10^{-3}$ \\
Observed residence time in channel (s) & 174 & 174 \\
Calculated residence time in channel $(\mathrm{s})$ & 183 & 183 \\
Estimated heat pulse velocity $\left(\mathrm{m} \mathrm{s}^{-1}\right)$ & $1.9 \times 10^{-3}$ & - \\
True heat pulse velocity $\left(\mathrm{m} \mathrm{s}^{-1}\right)$ & $1.5 \times 10^{-3}$ & - \\
Slug Temperature $\left({ }^{\circ} \mathrm{C}\right)$ & 96.0 & 21.5 \\
Max upstream temperature change $\left({ }^{\circ} \mathrm{C}\right)$ & 3.6 & 0.5 \\
Max downstream temperature change $\left({ }^{\circ} \mathrm{C}\right)$ & 2.3 & 0 \\
\hline
\end{tabular}




\section{Figures}

a. Data acquisition and tank geometry

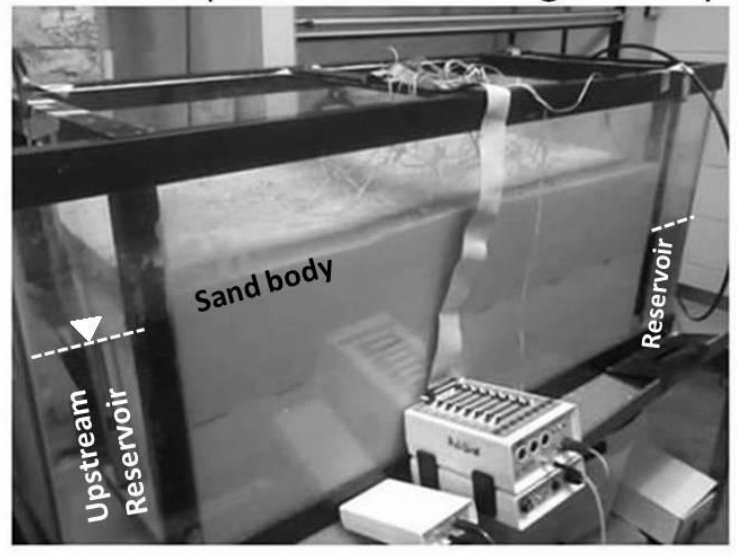

b. Coarse channel electrodes

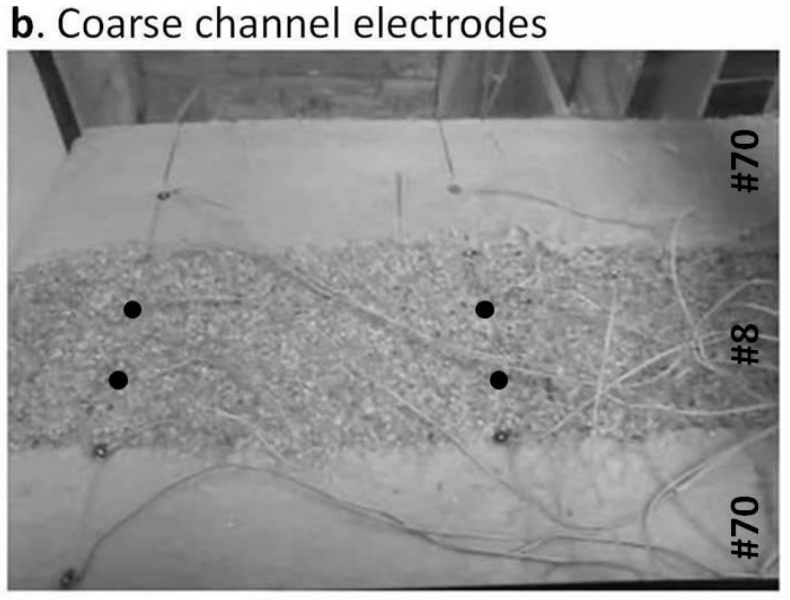

d. Reservoir Instrumentation

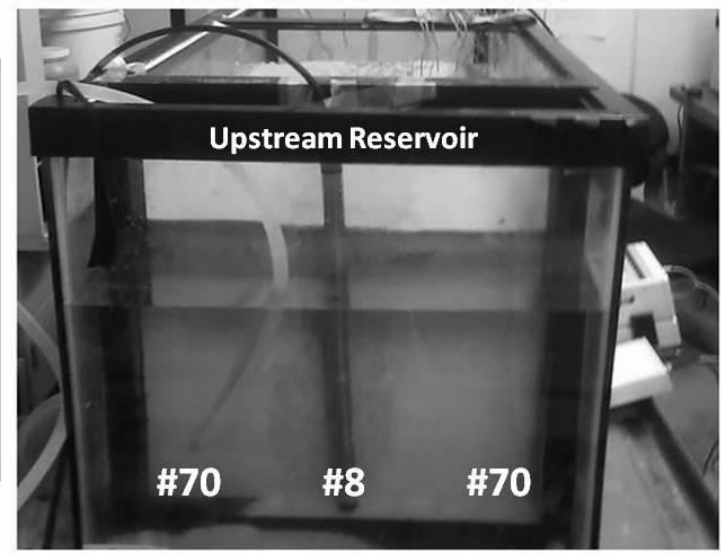

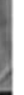

c. Scheme of electrode layout

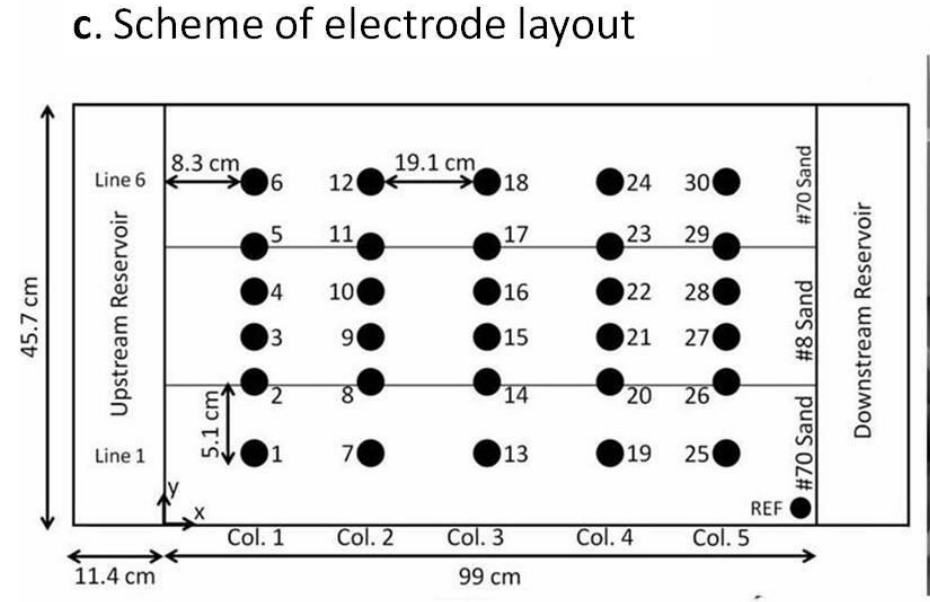

Figure 1. Illustration of the experimental setup. a. Photo of the experimental sand tank with BioSemi EEG measurement system (electroencephalographic multichannel voltmeter). b. Photo of the sand body showing the coarse \#8 sand of the preferential flow channel, between the flanking \#70 fine sand units. Also shown are the potential electrodes of the first two columns in the electrode grid Electrode positions in the channel are annotated. c. Surface view of the electrode layout showing positions of individual electrodes and the coarse channel. d. Photo of the temperature and pressure loggers used in the reservoirs. Note the logger position relative to the coarse channel. 
a. Hydraulic gradient in the tank

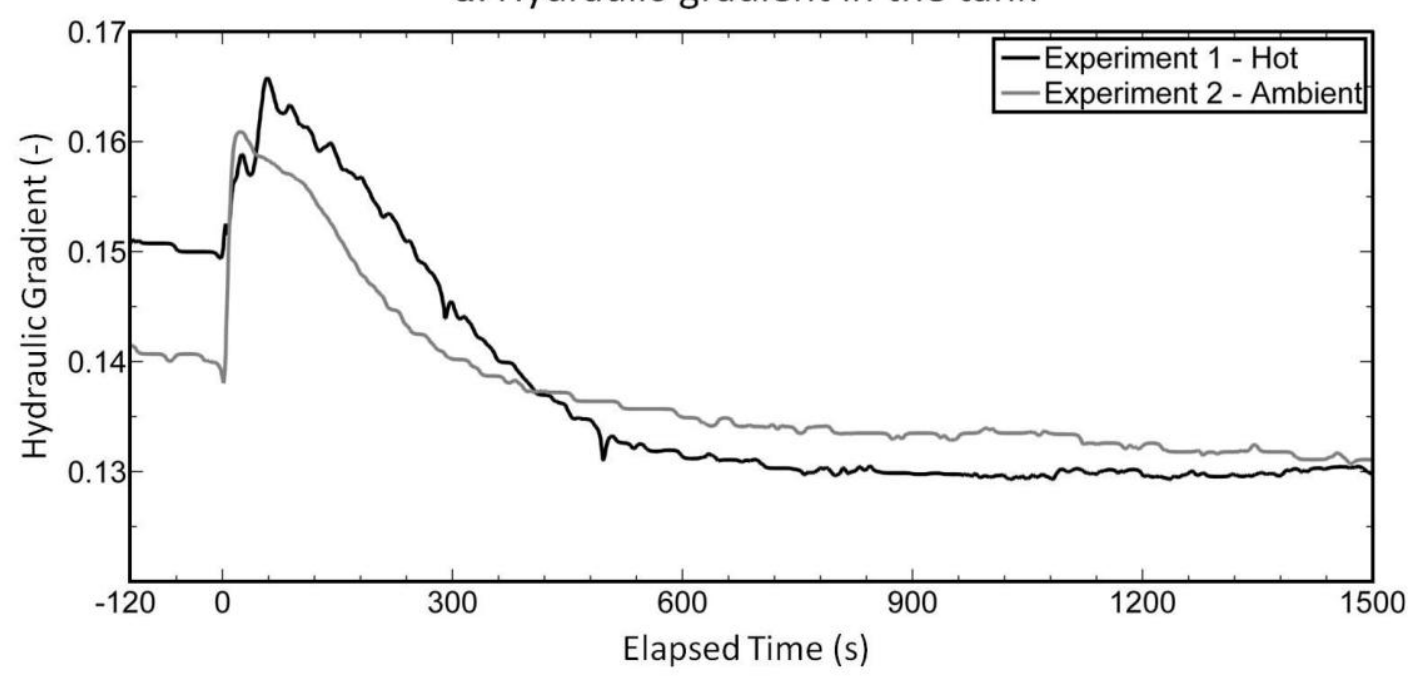

b. Temperature change in reservoirs after hot injection

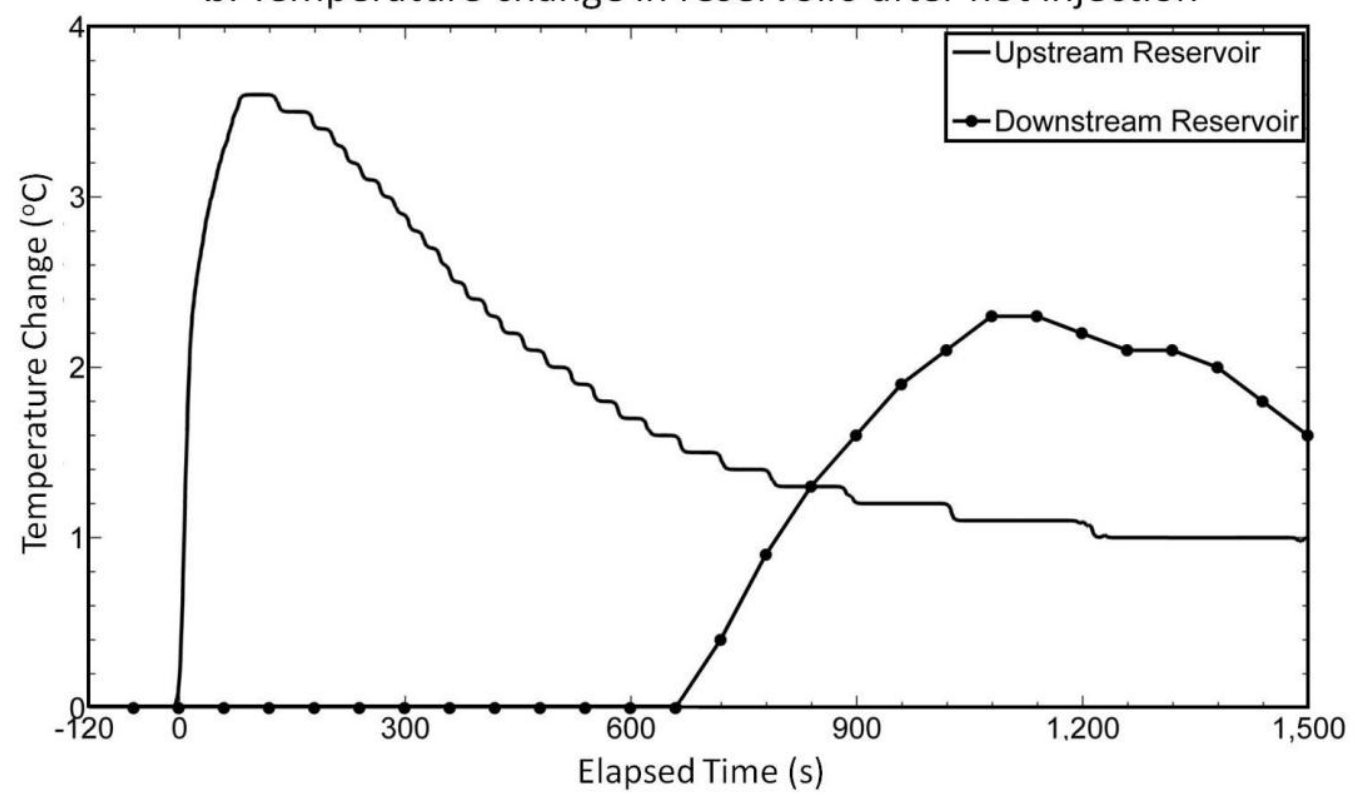

870 Figure 2. Hydraulic and temperature data measured in reservoirs during Experiments \#1 871 (injection of hot water) and Experiment \#2 (injection of water at ambient temperature). a. 872 Hydraulic gradient versus time for both experiments. The hydraulic disturbance produced by 873 each injection is comparable in time, and changes back to equilibrium in a consistent fashion 874 through time at approximately $t=600 \mathrm{~s}$. b. Temperature change in reservoirs after the injection 875 of the hot water (Experiment \#1). The temperature breakthrough is observed in the downstream 876 reservoir at $t=668 \mathrm{~s}$. The temperature in the upstream reservoir was increased by $3.6{ }^{\circ} \mathrm{C}$ and the 877 temperature of the downstream reservoir was increased by $2.3{ }^{\circ} \mathrm{C}$ during the experiment. 
879

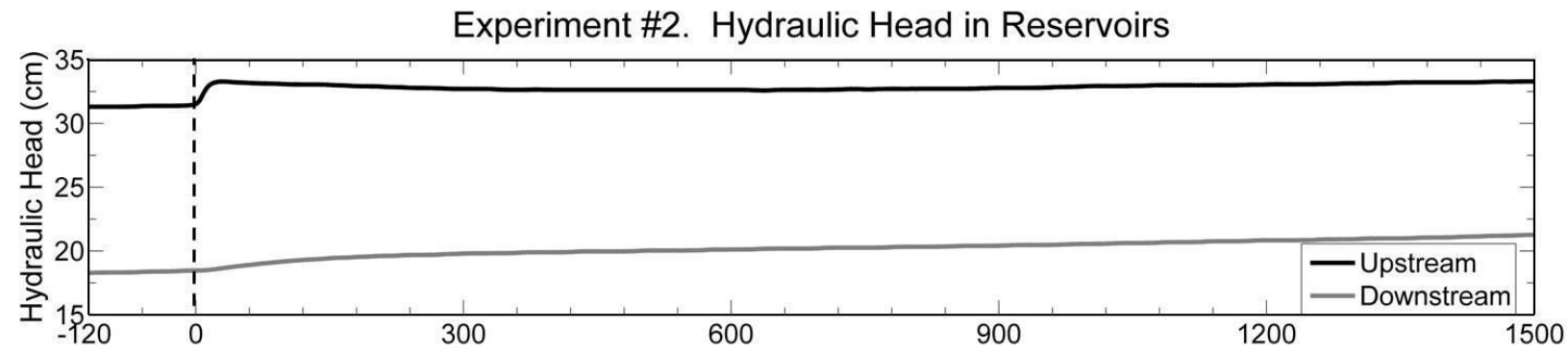

Experiment \#1. Hydraulic Head In Reservoirs

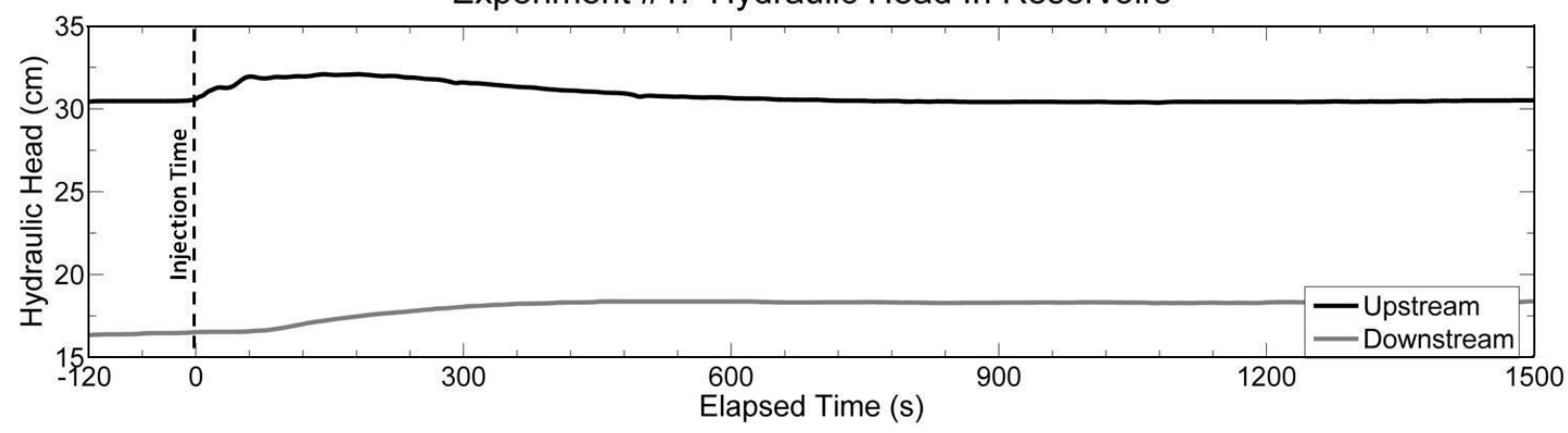

881 Figure 3. Evolution of the pressure heads in the two reservoirs in Experiments \#1 and 2. Very 882 small pressure head variations (less than $3 \mathrm{~cm}$ ) are produced in the two reservoirs in both 883 experiments.

884

885 
Electric Potential at Electrode 10
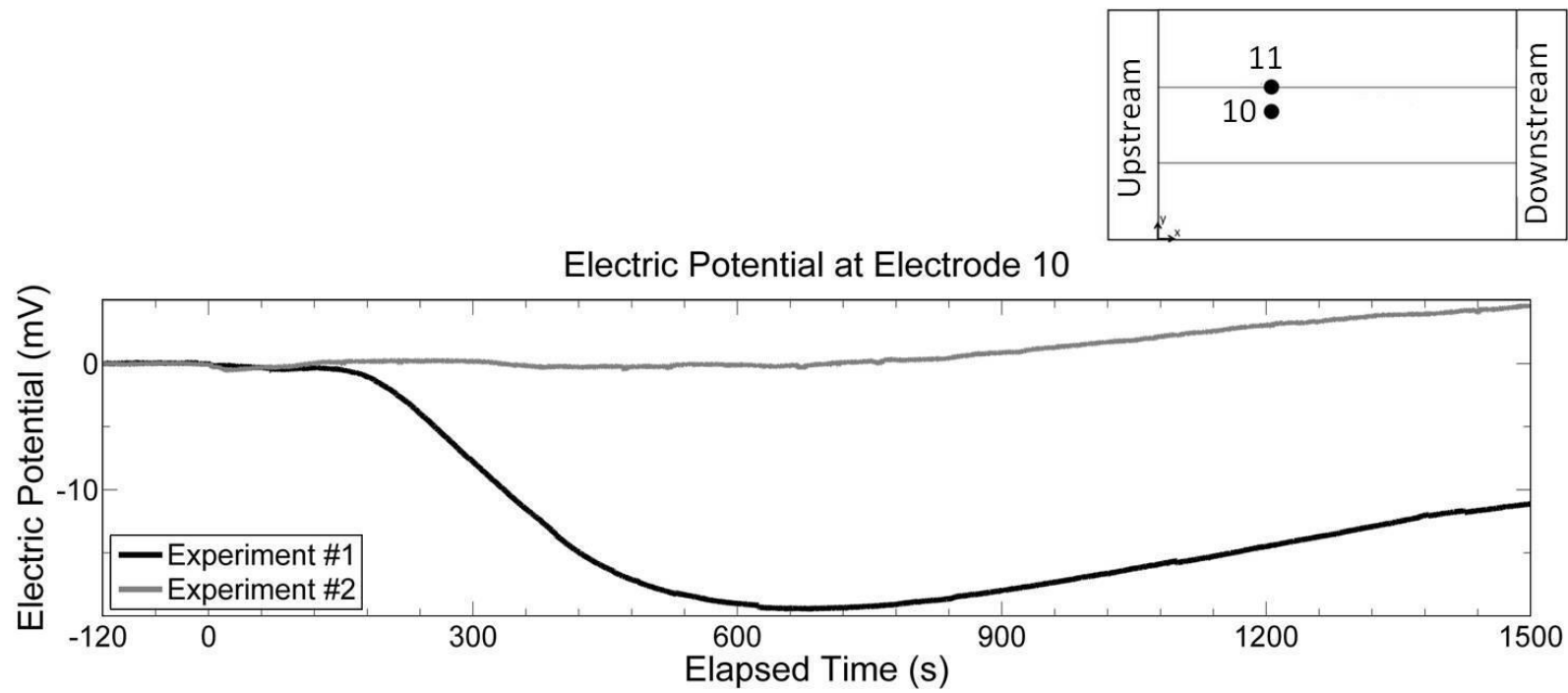

Electric Potential at Electrode 11

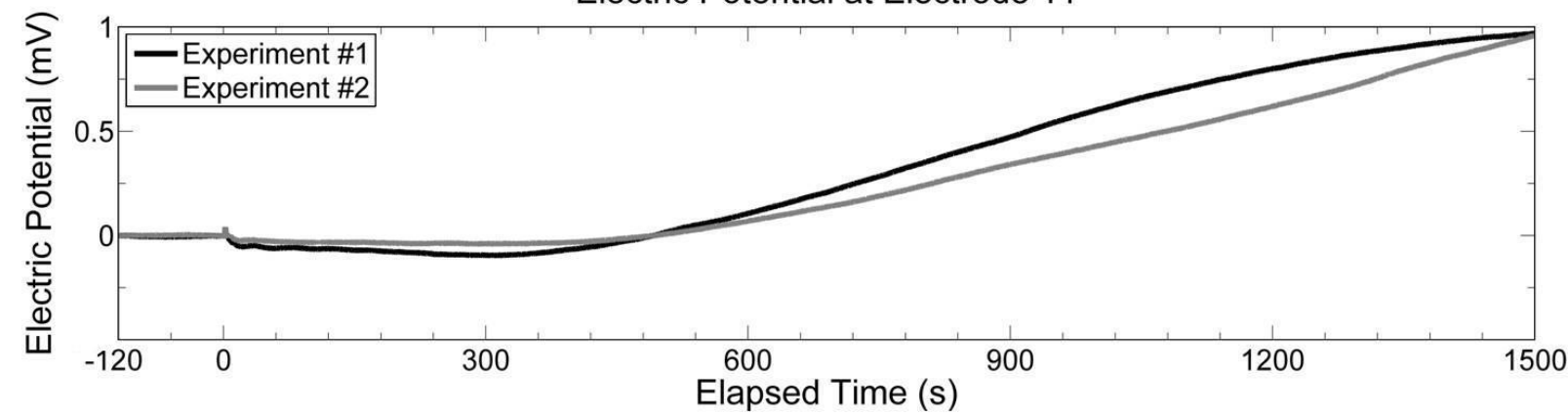

887 Figure 4. Processed data for selected electrodes. During both experiments the slug was injected 888 at time $\mathrm{t}=0 \mathrm{~s}$, after collecting $120 \mathrm{~s}$ of background data. The black curve shows the electric 889 potential recorded during experiment \#1 after injection of the hot water, and the gray curve 890 shows the electric potential recorded during experiment \#2. Electrode 11 at the boundary 891 between the coarse channel and the fine sand unit. Electrode 11 shows little variability from one 892 injection to the next, indicating consistent experimental conditions, and a minor influence due to 893 the presence of the heat, which is confined primarily to the channel. Note the large difference in 894 scale on the potential axis, reflecting the direct influence of heat in the coarse channel on the 895 potentials recorded at channel electrodes. 
a. Processed Data for Coarse Channel Electrodes. Experiment \#1

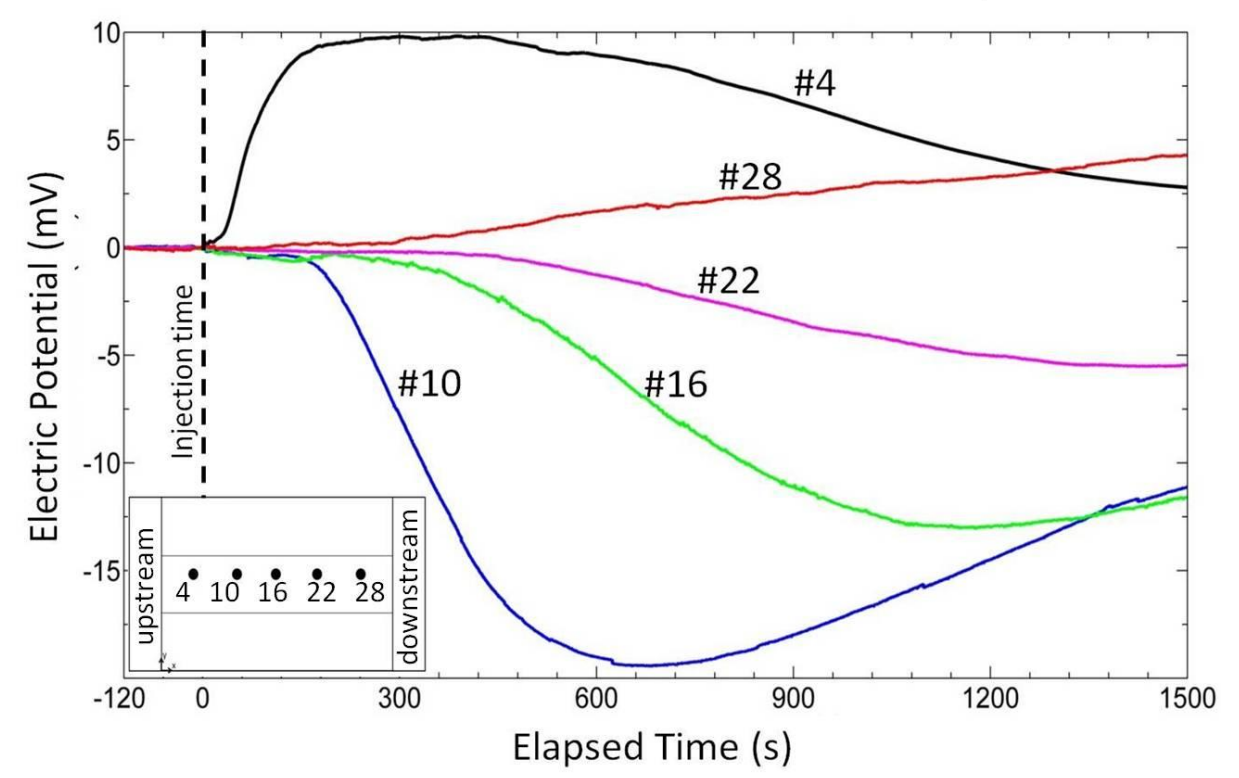

b. Raw Data for Coarse Channel Electrodes. Experiment \#1

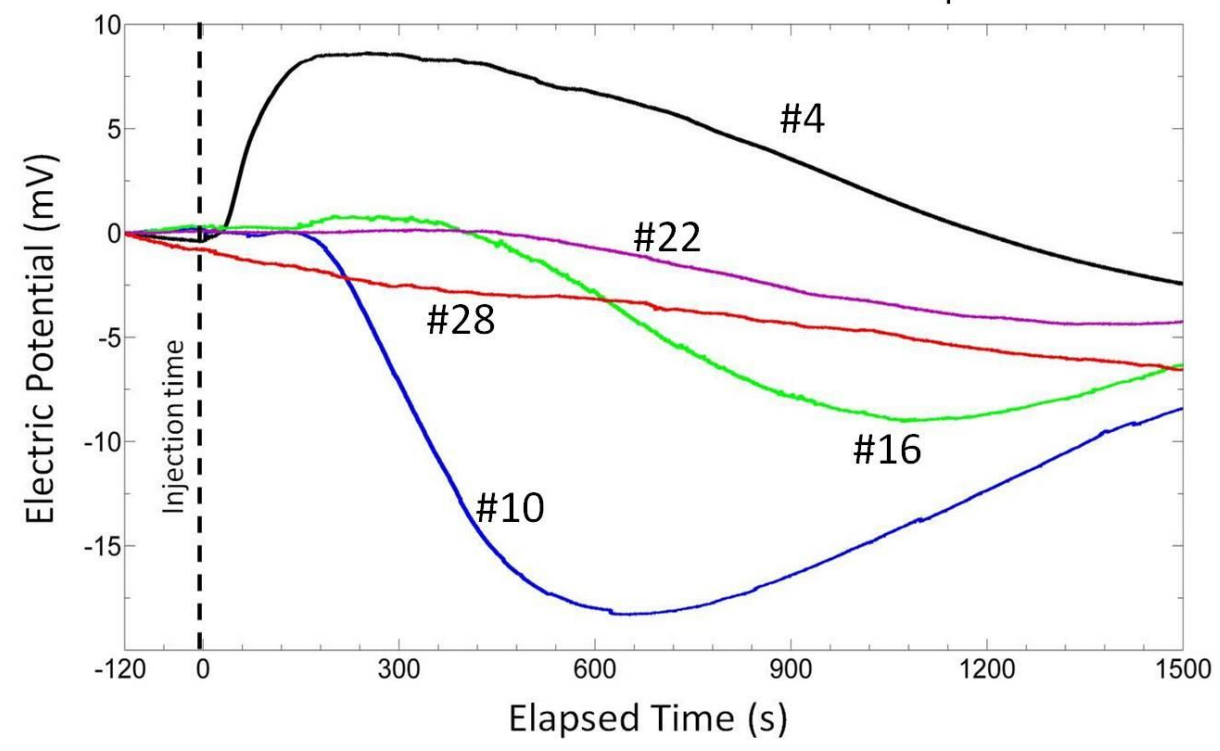

Figure 5. Time-lapse record of electric potential in coarse channel electrodes. a. Processed data showing the change from background. These data have been decimated, filtered and corrected for linear background drift. These data show the electric potential anomaly in the coarse channel observed after the hot injection. The effect of increased temperature is apparent in electrodes 10, 16 and 22, by the sudden decrease in potential. b. Raw data prior to decimation, filtering and 


\section{Experiment \#1. Hot Water Injection.}

Time $0 \mathrm{~s}$

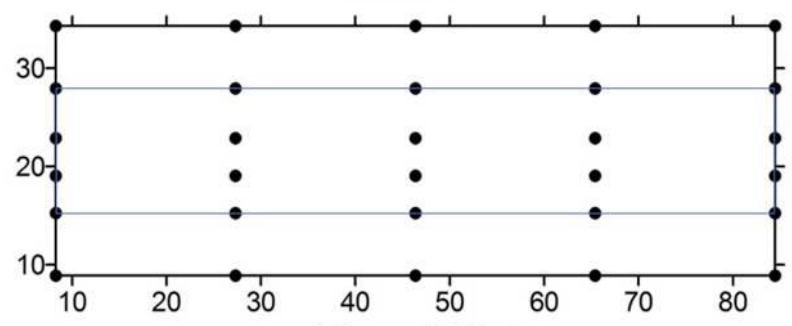

Time $600 \mathrm{~s}$

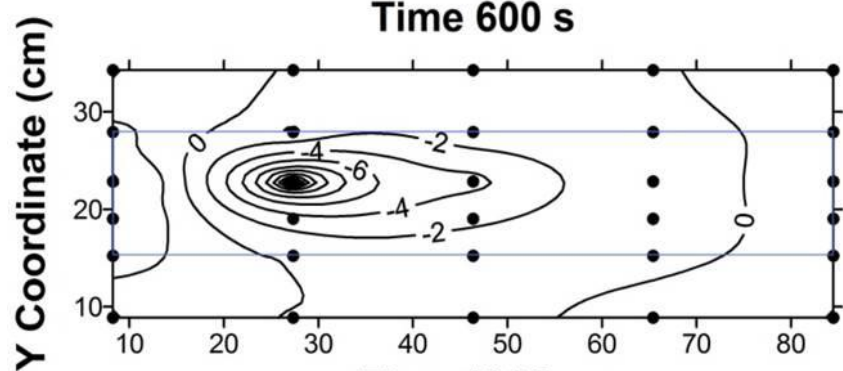

Time $1200 \mathrm{~s}$

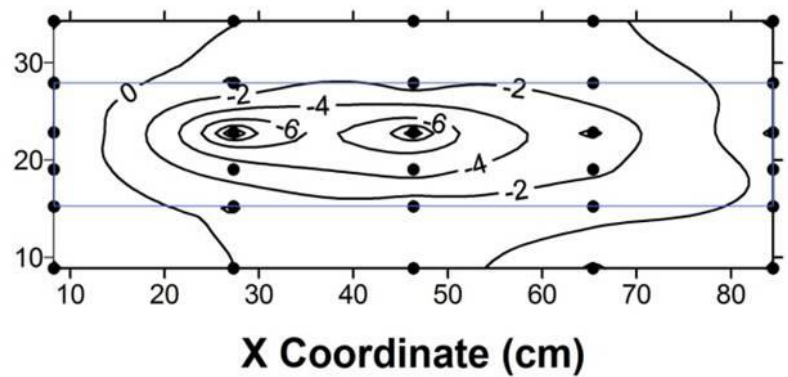

905

906

907

908

909

910

911 channel.
Time $300 \mathrm{~s}$

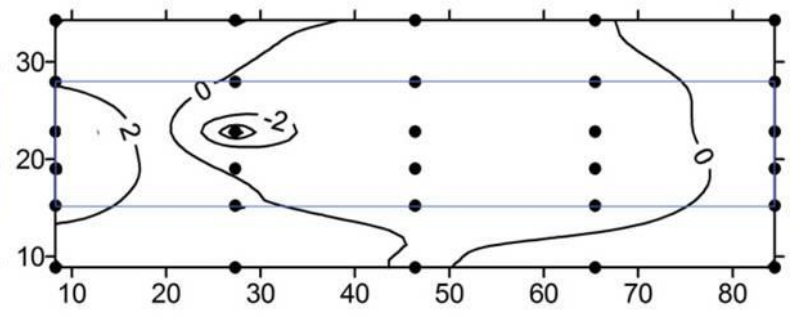

Time $900 \mathrm{~s}$

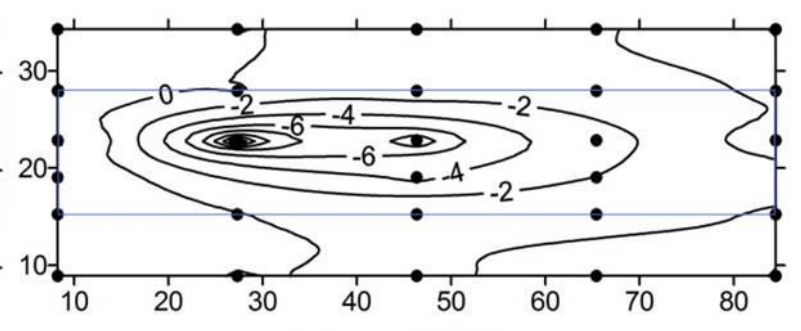

Time $1500 \mathrm{~s}$

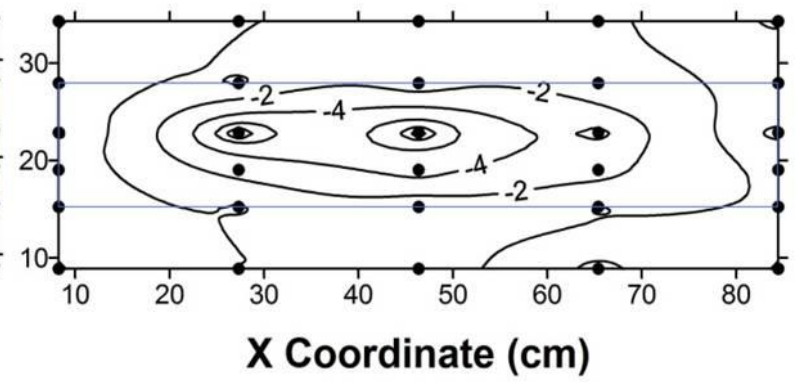

$X$ Coordinate $(\mathrm{cm})$

Figure 6. Time-lapse surface maps of electric potential showing the growth of the total anomaly following the injection of the hot water in experiment \#1. The sign and magnitude of the total anomaly are therefore dependent on the relative influences of pressure head and temperature. The anomaly is clearly negative relative to the background potential and localizes the coarse 


\section{a. Modeled Steady-State Electrokinetic Field}

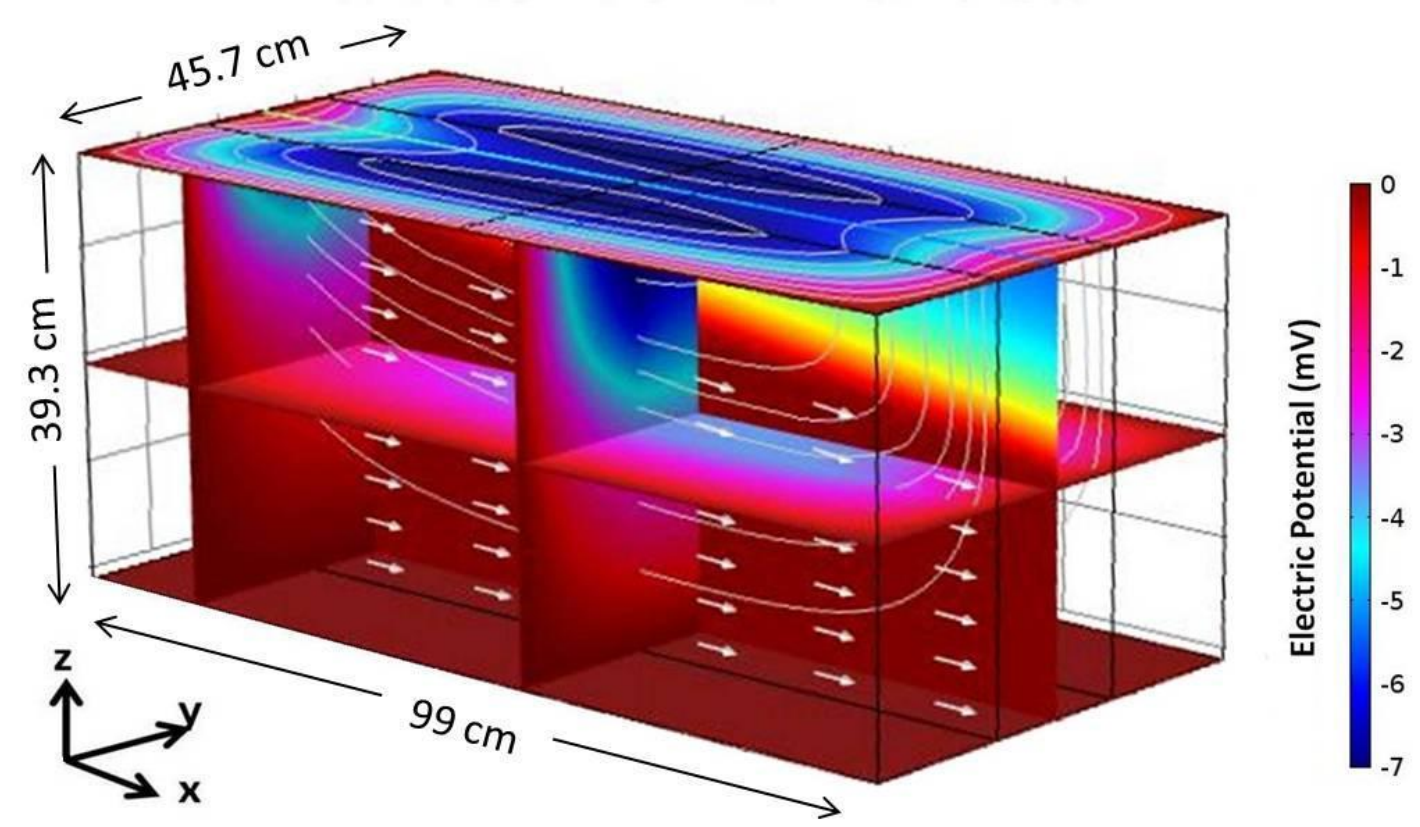

\section{b. Modeled Steady-State Electrokinetic Field in the Channel}

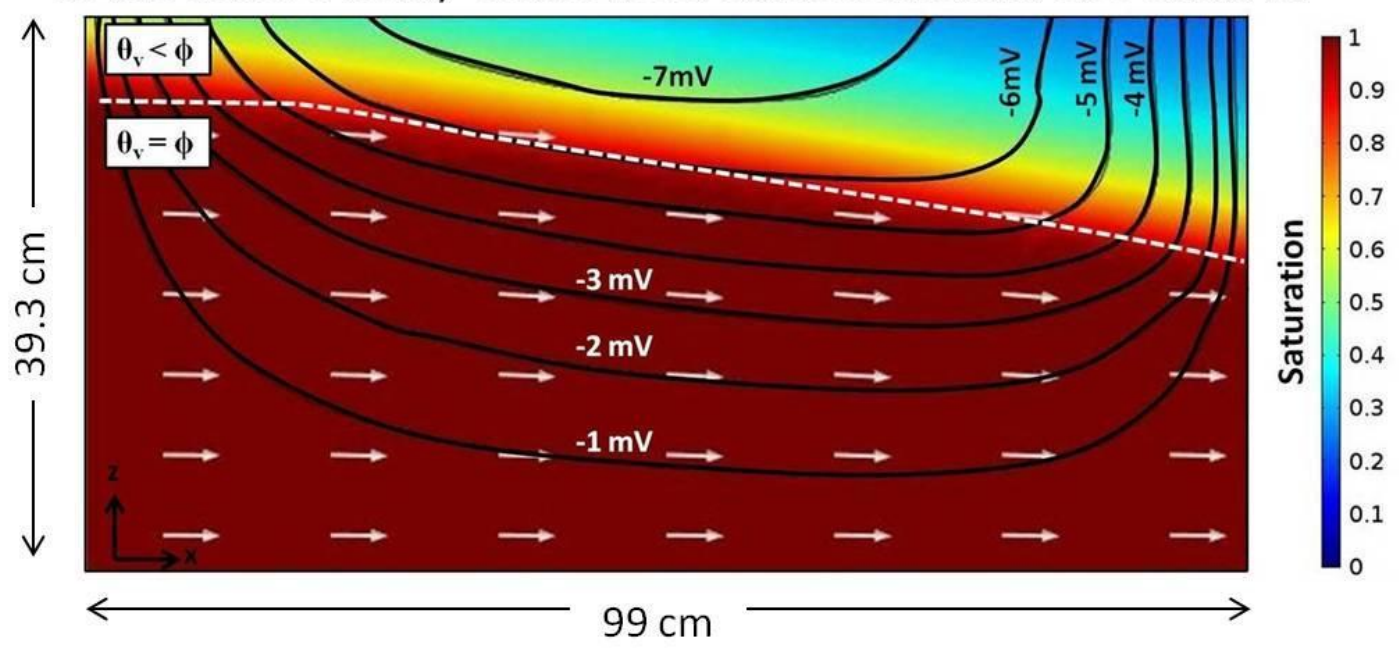

Figure 7. Steady state simulation of saturation and electric potential simulated from parameters given in Table 1. a. Steady-state electric potential at the surface and longitudinal water saturation $s_{w}$ in the sandbox. The white vectors show the water velocity profile. b. Longitudinal steadystate saturation profile and electric potential contours inside the coarse channel. Note the general small negative background self-potential anomaly at the top surface of the tank. The longitudinal saturation profile is shown on the $(x, z)$-plane, and electric potential is shown on the $(x, y)$ and $(y$, z)-planes. 


\section{Experiment \#2. Evolution of Electric Potential during Hydraulic Disturbance}
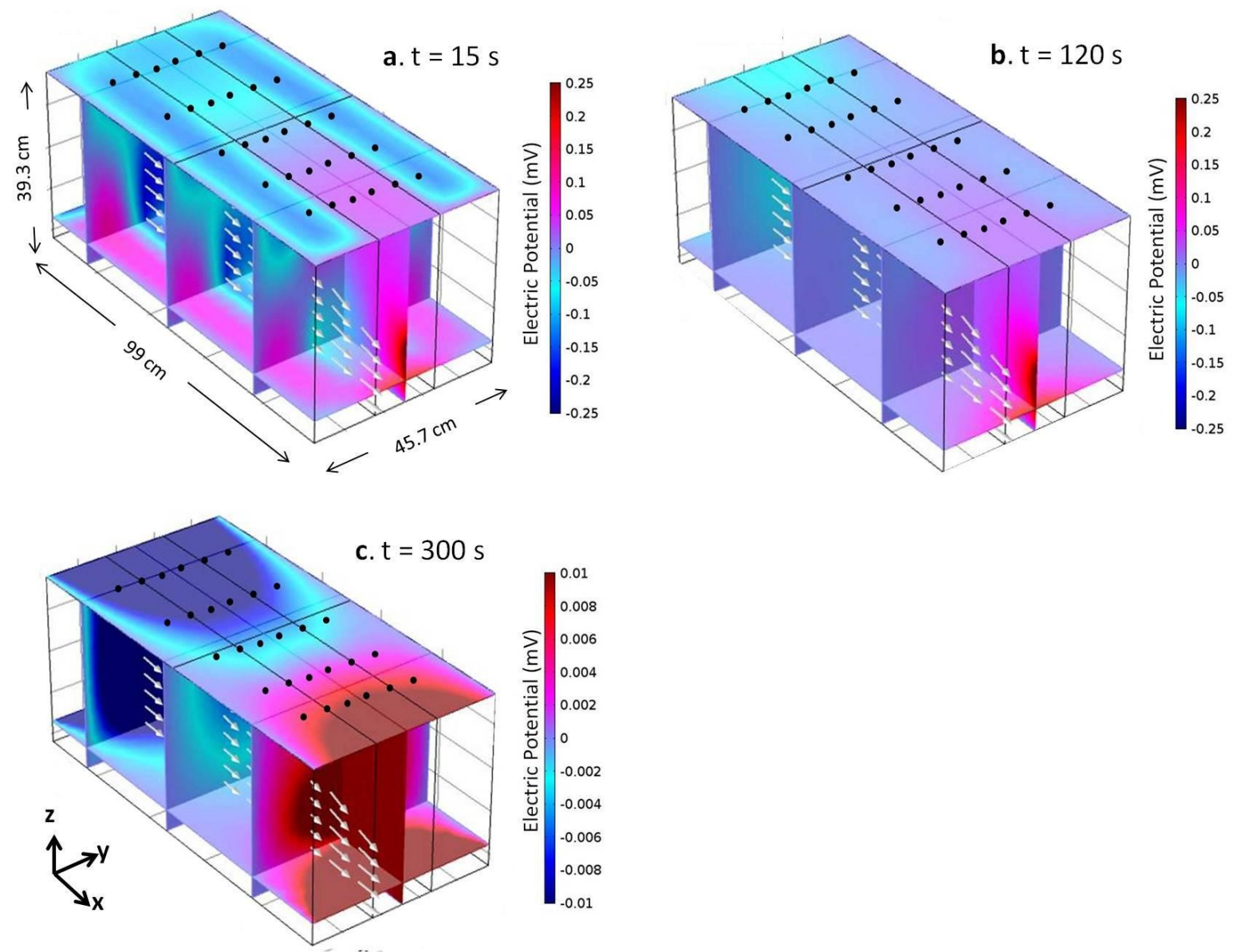

Figure 8. Simulation of Expriment \#2 showing electric potential changes relative to the background self-potential signals (see Figure 7) through the duration of the hydraulic disturbance created by the injection. The modeled electrical potential change due to the ambient injection is negligible compared to the change simulated from the hot injection. a. Time $t=15 \mathrm{~s}$ corresponding to the peak hydraulic gradient. b. Time $t=120 \mathrm{~s}$ corresponding the falling limb of the hydraulic disturbance. c. Time $t=300 \mathrm{~s}$ corresponding to the end of the hydraulic disturbance when the hydraulic gradient is near steady-state. The modeled anomaly at the surface is one order of magnitude smaller than on the upstream and downstream faces. The white vectors show the water velocity profiles. 
Experiment \#1. Hot Water Injection.
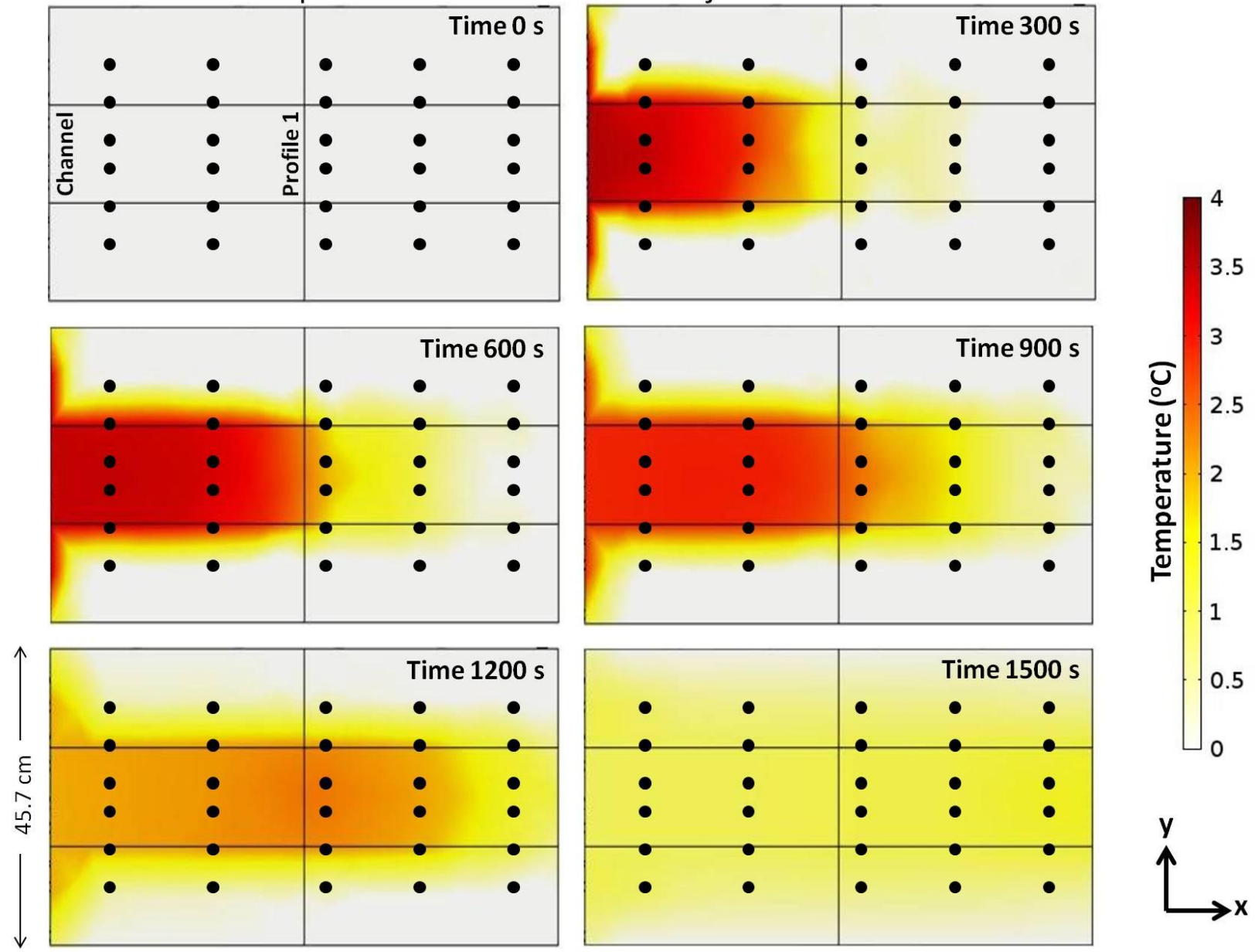

Figure 9. Simulated time-lapse snapshots of temperature changes at the top surface of the tank, relative to the background temperature, due to the hot injection. The temperature change is primarily confined to the coarse channel. 
Experiment \#1. Hot Water Injection.
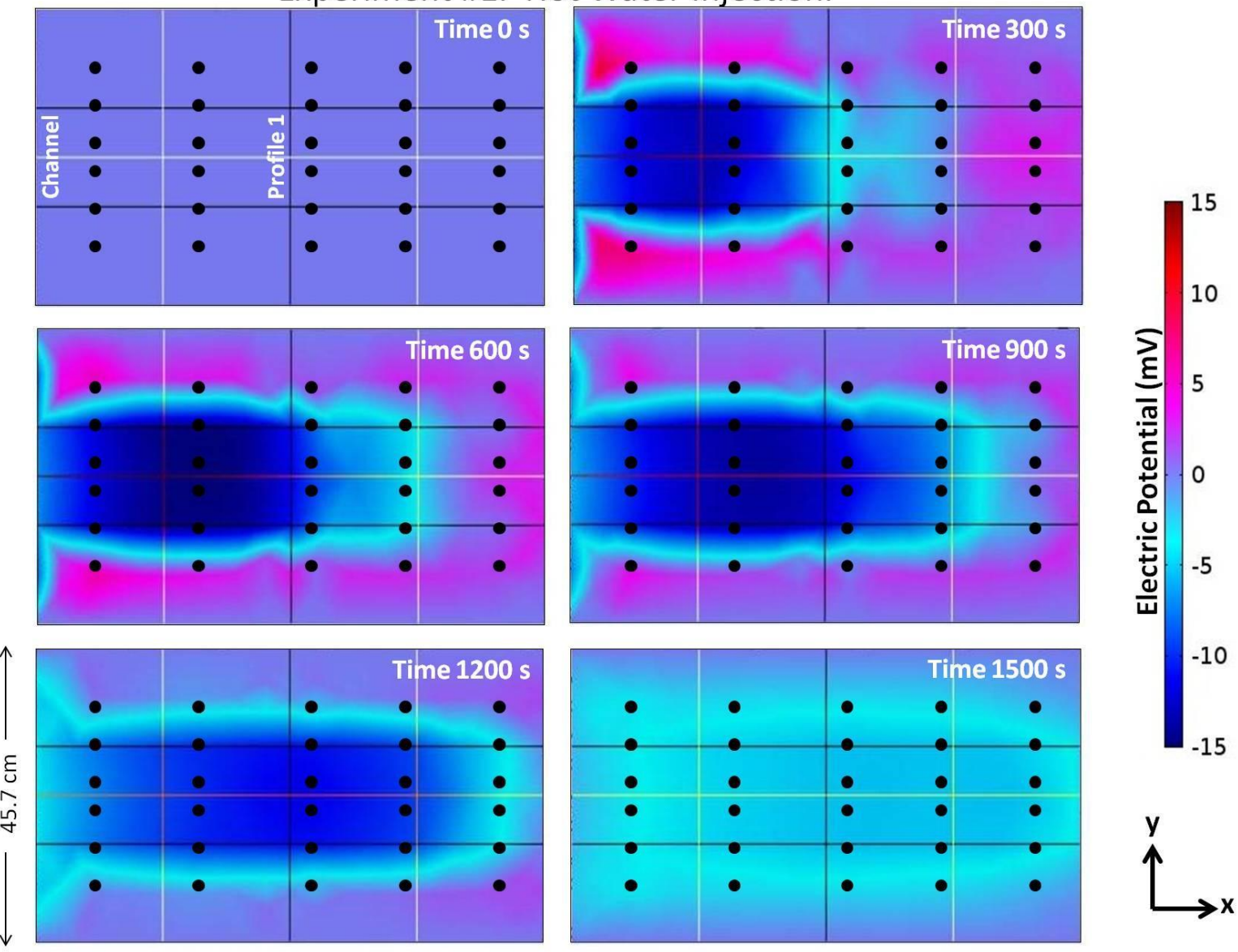

Figure 10. Snapshots of electric potential change at the surface of the sandbox. The electric potential anomaly is negative and grows in time as the temperature in the channel changes. The electric potential and temperature are tracked through time along Profile 1 . The computations are done with a value of the thermoelectric coupling coefficient of $-5 \mathrm{mV}^{\circ} \mathrm{C}^{-1}$. 
3D simulation of temperature and electric potential anomalies

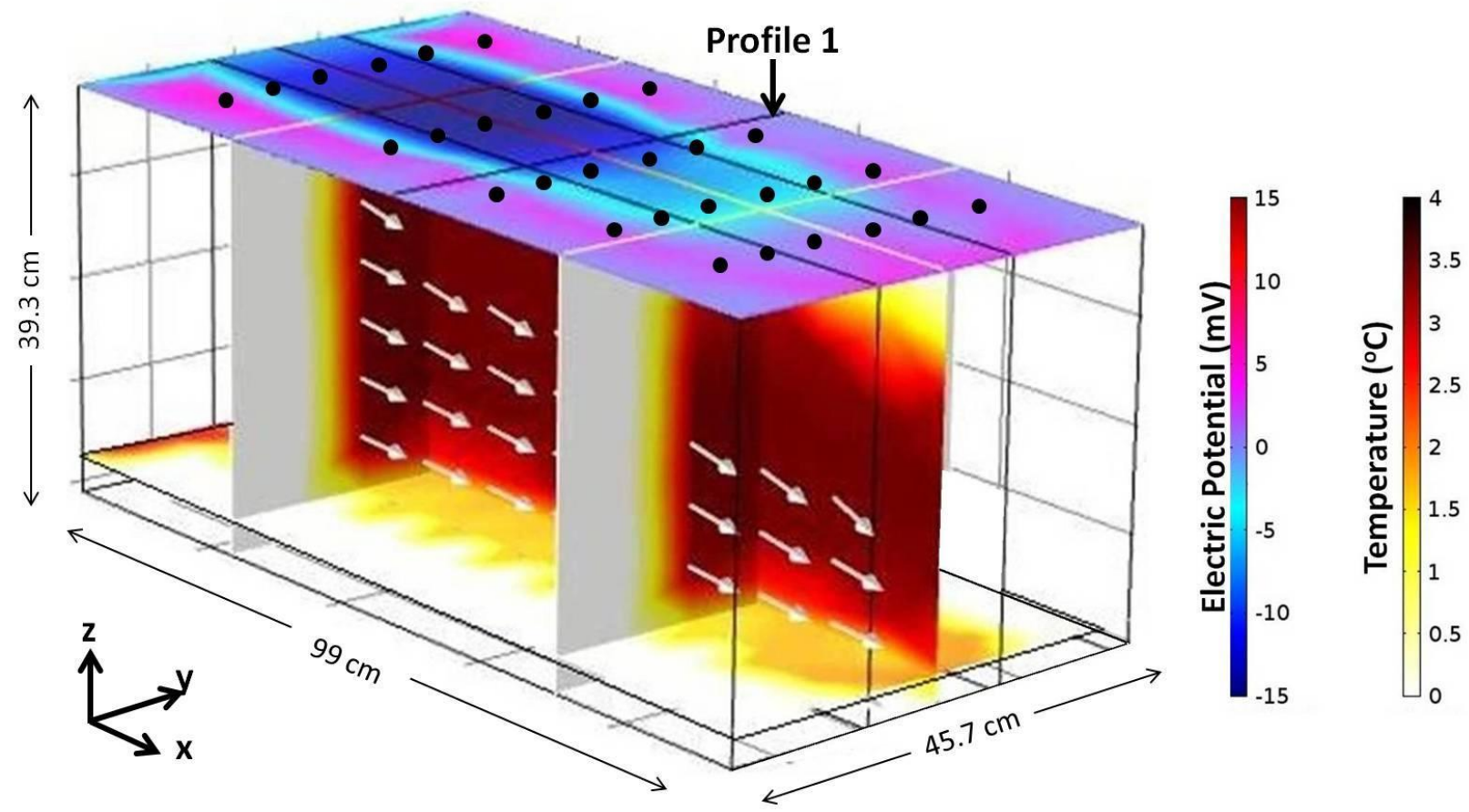

Figure 11. Time-lapse simulation of electric potential in the tank, relative to the background, following the hot injection. The simulation shows the 3D growth of the negative potential anomaly in the channel at the surface of the tank. This anomaly is due to the temperature distribution in the channel in the subsurface. The color of the upstream and downstream crosslines parallel to Profile 1 give an indication of the temperature inside of the channel. The position of the electrodes is shown at the top surface of the simulated tank. 
a. Modeled Temperature along Profile 1.

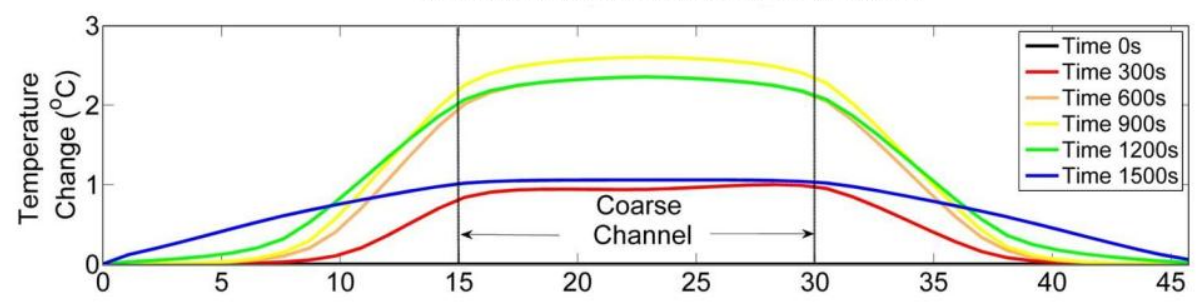

b. Modeled Electric Potential along Profile 1.

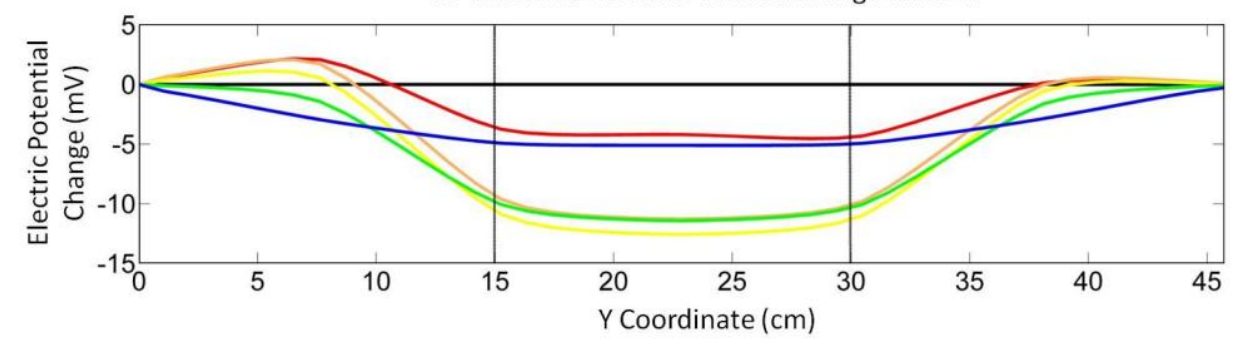

c. Modeled Electric Potential vs. Modeled Temperature along Profile 1.

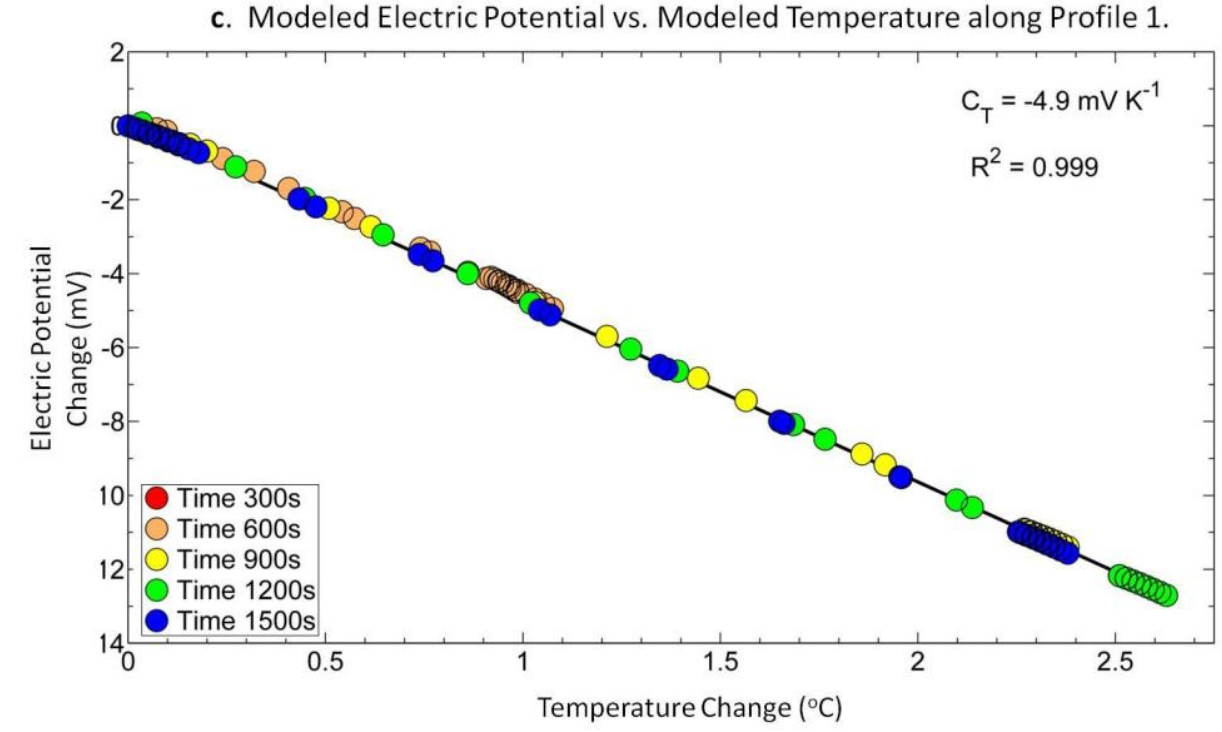

Figure 12. Simulated temperature and electric potential changes relative to background along Profile 1 (see position in Figure 11) following the injection of the hot water. a. Simulated temperature change relative to background. The temperature anomaly is confined primarily to the coarse channel. b. Simulated electric potential change relative to background following the hot injection. The electric potential anomaly is negative, achieves a peak amplitude of approximately $-13 \mathrm{mV}$, and is confined primarily to the permeable channel. c. Simulated relationship between temperature change and electric potential change along profile 1 . The relationship is linear and has a slope of $-4.9 \mathrm{mV} \mathrm{K}^{-1}$, which is approximately equivalent to the thermo-electric (intrinsic) coupling coefficient of $C_{T}=-5 \mathrm{mV} \mathrm{K}^{-1}$ incorporated into the model, indicating the potential anomaly is due to the temperature change in the tank for this simulation. Times 1 to 5 are those given in Figures 9 and 10 . 


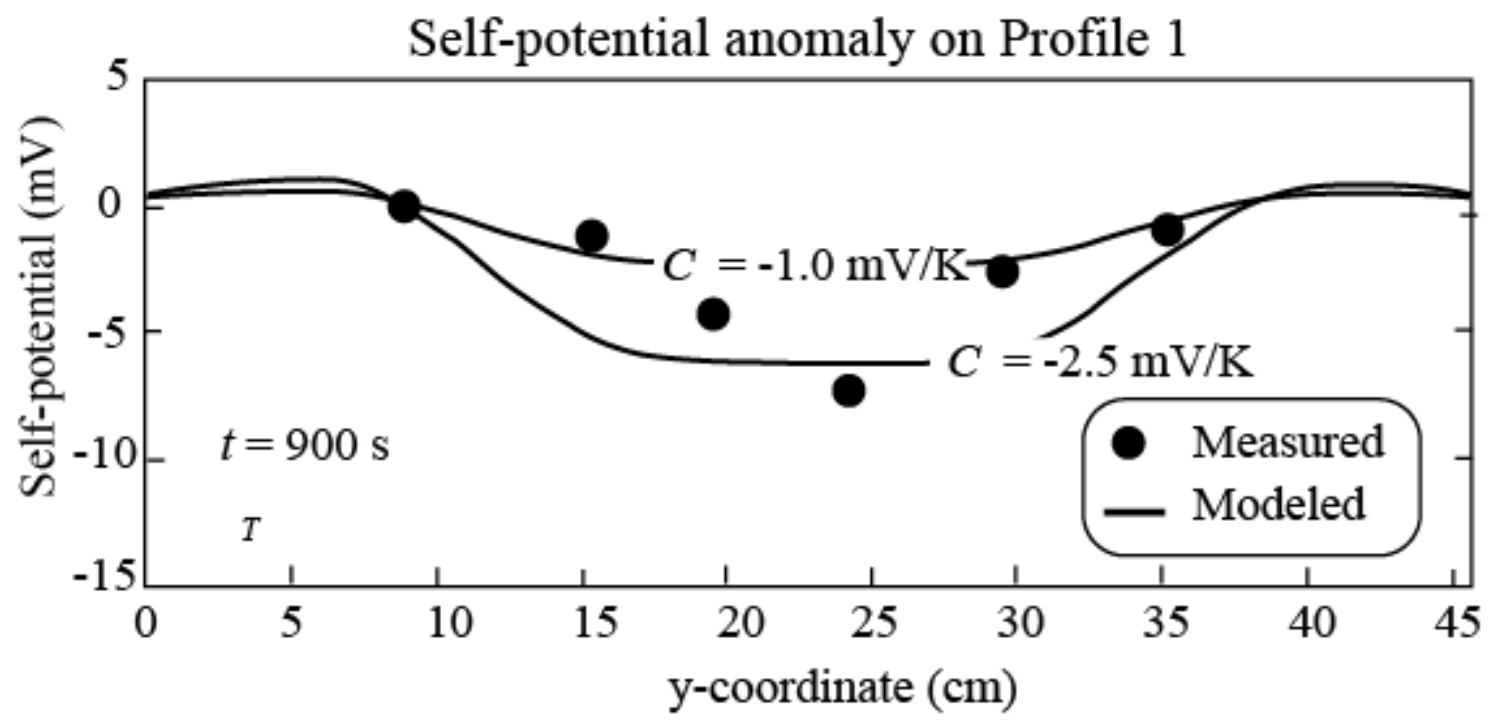

Figure 13. Compariosn between the simulated self-potential anomaly for Profile 1 (see position 977 on Figure 11) and the measured self-potential data at time $900 \mathrm{~s}$. We used a thermoelectric 978 coupling coefficient of $-2.5 \mathrm{mV} \mathrm{K}^{-1}$ and $-1.0 \mathrm{mV} \mathrm{K}^{-1}$ for the simulation with no attempt to 979 optimize this parameter. The observed effect is a combination of the intrinsic thermoelectric 980 effect plus the effect associated with the temperature dependence of the potential of the $\mathrm{Ag} / \mathrm{AgCl}$ 981 electrodes with temperature.

982

983 


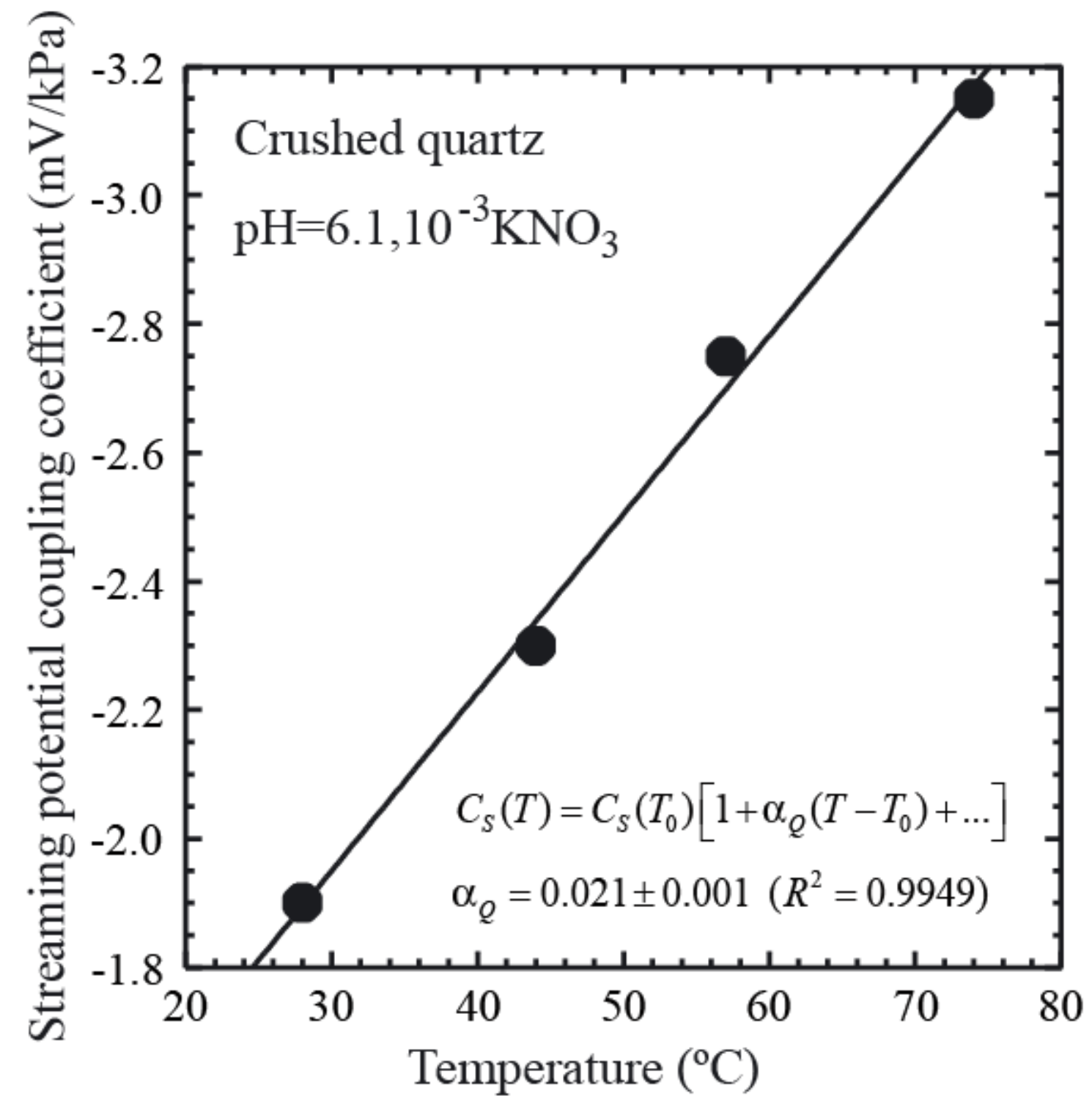

987 Figure 14. Temperature dependence of the streaming potential coupling coefficient. The 988 experimental data are from Ishido and Mizutani (1981) and we considered only the data at 989 thermodynamic equilibrium. 


\section{Temperature effect on Streaming Potential Coupling Coefficient}

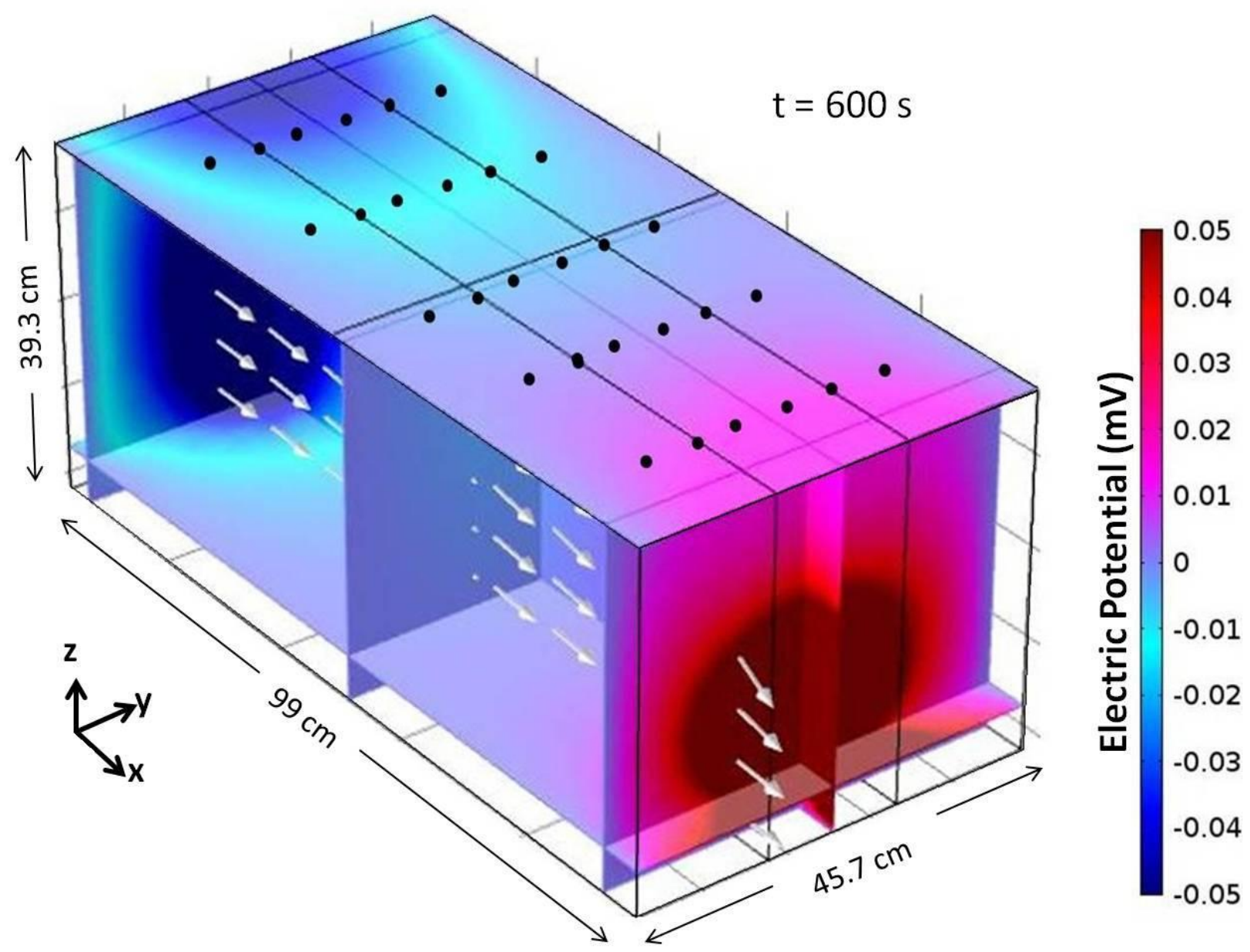

993 Figure 15. Simulation of the self-potential response using the thermal dependency of the 994 streaming potential coupling coefficient shown in Figure 14. The resulting self-potential anomaly 995 is very small compared to the thermoelectric effect. 
Graphical Abstract

4D simulation of temperature and resulting self-potential anomaly

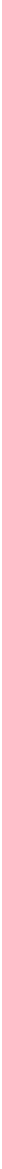

